\title{
Self-assembly of a peptide amphiphile containing l-carnosine and its mixtures with a multilamellar vesicle forming lipid
}

Article

Accepted Version

Castelletto, V., Cheng, G., Stain, C., Connon, C. and Hamley, I. (2012) Self-assembly of a peptide amphiphile containing Icarnosine and its mixtures with a multilamellar vesicle forming lipid. Langmuir, 28 (31). pp. 11599-11608. ISSN 0743-7463 doi: https://doi.org/10.1021/la302210b Available at https://centaur.reading.ac.uk/28942/

It is advisable to refer to the publisher's version if you intend to cite from the work. See Guidance on citing.

To link to this article DOI: http://dx.doi.org/10.1021/la302210b

Publisher: American Chemical Society

All outputs in CentAUR are protected by Intellectual Property Rights law, including copyright law. Copyright and IPR is retained by the creators or other copyright holders. Terms and conditions for use of this material are defined in the End User Agreement.

www.reading.ac.uk/centaur 
Central Archive at the University of Reading

Reading's research outputs online 
Self-Assembly of a Peptide Amphiphile Containing L-Carnosine and its Mixtures with a Multilamellar Vesicle Forming Lipid.

\author{
V. Castelletto ${ }^{\dagger,{ }^{\star}}$, G. Cheng ${ }^{\dagger, \ddagger}$, C. Stain ${ }^{\#}$, C. J. Connon ${ }^{\dagger}$, I. W. Hamley ${ }^{\dagger,{ }^{*}}$ \\ ${ }^{\dagger}$ School of Chemistry, Food Science and Pharmacy, University of Reading, \\ Whiteknights, Reading RG6 6AD, UK \\ ${ }^{\ddagger}$ Currently at Department of Chemistry, University of Liverpool, Crown Street, \\ Liverpool L69 3BX, UK \\ " Centre for Advanced Microscopy, University of Reading, Whiteknights \\ Reading, RG6 6AF, UK
}

${ }^{*}$ Authors for Correspondence. 


\section{Abstract}

The self-assembly of the peptide amphiphile (PA) hexadecyl-(beta alaninehistidine) is examined in aqueous solution, along with its mixtures with multilamellar vesicles formed by DPPC (dipalmitoyl phosphatidylcholine). This PA, denoted $\mathrm{C}_{16^{-}}$ $\beta \mathrm{AH}$ contains a dipeptide headgroup corresponding to the bioactive molecule Lcarnosine. It is found to self-assemble into nanotapes based on stacked layers of molecules. Bilayers are found to coexist with monolayers in which the PA molecules pack with alternating up-down arrangement so that the headgroups decorate both surfaces. The bilayers become dehydrated as PA concentration increases and the number of layers in the stack decreases to produce ultrathin nanotapes comprising 23 bilayers. Addition of the PA to DPPC multi-lamellar vesicles leads to a transition to well-defined unilamellar vesicles. The unique ability to modulate the stacking of this $\mathrm{PA}$ as a function of concentration, combined with its ability to induce a multi-lamellar to uni-lamellar thinning of DPPC vesicles may be useful in biomaterials applications where the presentation of the peptide function at the surface of self-assembled nanostructures is crucial. 


\section{Introduction}

L-carnosine ( $\beta$-alanine-histidine, $\beta \mathrm{AH})$ is a naturally occurring dipeptide, first isolated from a meat extract, ${ }^{1-2}$ present in the muscle and brain tissues of humans and other vertebrates in relatively high concentrations.

Dipeptide $\beta$ AH has a range of biological activities. ${ }^{1-2}$ The $\beta$-alanine $\beta A$ residue in $\beta \mathrm{AH}$ can react directly with oxidized carbohydrates and lipids, ${ }^{3}$ and is therefore implicated in antioxidant properties for these species. ${ }^{4-6}$ The antioxidant properties of the dipeptide ${ }^{5}$ are also able to delay senescence of cultured cells. ${ }^{7}$ The histidine $(\mathrm{H})$ residue in $\beta \mathrm{AH}$ has the ability to bind to transition metal ions ${ }^{8-11}$ or to inhibit glycation-induced protein cross-linking. ${ }^{12}$ In particular, the prevention of crosslinking has a protective effect in inhibiting fibrillisation of $\alpha$-crystallin during the formation of cataracts. ${ }^{13-14}$ This property may also be important in the proposed application of $\beta A H$ to treat Alzheimer's disease. ${ }^{12}$

Peptide $\beta$ AH is highly water soluble, but it does not self assemble in water. ${ }^{15}$ Therefore, in view of the wide range of biological activities of $\beta \mathrm{AH}$, the construction of novel $\beta A H$ supramolecular self assemblies is a crucial step to expand the potential biochemical activities of this peptide.

We have recently ${ }^{15}$ explored the use of the bulky aromatic Fmoc $[\mathrm{Fmoc}=\mathrm{N}-$ (fluorenyl-9-methoxycarbonyl)] unit as a structure-directing agent to induce fibrillisation of $\beta \mathrm{AH}$. We showed that Fmoc- $\beta \mathrm{AH}$ forms well defined amyloid fibrils containing $\beta$-sheets above a critical aggregation concentration.

An alternative strategy to drive $\beta A H$ self assembly involves turning the dipeptide into a peptide amphiphile (PA) through the lipidation of $\beta A H$. PA-based materials are attracting immense attention due to diverse range of demonstrated potential applications in regenerative medicine. ${ }^{16-21}$ It is expected that the self assembly of the lipid- $\beta A H$ will be driven by the hydrophobicity of the lipidated chain. 
There is only one report in the literature about lipidated $\beta A \mathrm{H}^{22}$ In that work, potential cosmetic applications of $\mathrm{C}_{16}-\beta \mathrm{AH}$ were demonstrated since the PA is able to diffuse into the stratum corneum and the epidermal and dermal skin layers.

Here, we explore the use of the $\mathrm{C}_{16}$ palmitoyl lipid chain as a structuredirecting agent to induce fibrillisation of carnosine. We investigate the self-assembly of $\mathrm{C}_{16}-\beta \mathrm{AH}$ using a variety of spectroscopic and microscopic techniques, and compare it to the self assembly of Fmoc- $\beta \mathrm{AH}$ or the behaviour of $\beta \mathrm{AH}$ in water. A PA with a palmitoyl chain is chosen for study since it is compatible with the lipid chain length in DPPC for our study on incorporation in vesicles, and also because $C_{16}$ chains are capable to drive self-assembly due to amphiphilicity, whereas shorter lipid chains may not be, and longer lipid chains can show restricted dynamics and/or crystallization.

In addition, we describe the utility of multilamellar vesicles (MLVs) for $\mathrm{C}_{16^{-}}$ $\beta \mathrm{AH}$ delivery and stabilization. We examine dipalmitoylphosphatidylcholine (DPPC) MLVs as a model system to incorporate $C_{16}-\beta A H$, with the potential for applications in delivery to cells. In particular, we investigate the incorporation of $C_{16}-\beta A H$ into DPPC vesicles at $C_{16}-\beta A H$ concentrations higher than the PA self assembly concentration.

\section{Experimental}

\section{Materials.}

Palmitic acid was purchased from TCl Europe. L-Carnosine, $\mathrm{N}$-hydroxysuccinimide (HOSu), 1,3-dicyclohexylcarbodiimide (DCC), triethylamine and DPPC were purchased from Sigma-Aldrich (UK); acetonitrile (HPLC grade), tetrahydrofuran (THF) and water (HPLC) were purchased from Fisher Scientific (UK).

Synthesis of $\boldsymbol{C}_{16}-\beta A H$. The $\mathrm{C}_{16}-\beta \mathrm{AH}$ (Scheme 1 ) was synthesized by reaction of Lcarnosine in the co-solvent of acetonitrile and water (1:2) in the presence of triethylamine with the NHS ester of palmitic acid, which was prepared by treatment of 
palmitic acid with $\mathrm{N}$-hydroxysuccinimide $(\mathrm{HOSu})$ in the presence of dicyclohexylcarbodiimide (DCC) in THF at room temperature. The obtained crude product was purified by semi-preparative RP-HPLC on a Discovery® BIO wide pore C18 SUPELCO HPLC Column $(10 \mu \mathrm{m}$ particle size, $\mathrm{L} \times \mathrm{I} . \mathrm{D} .15 \mathrm{~cm} \times 10 \mathrm{~mm})$ using a mobile phase of HPLC grade water and acetonitrile with $0.1 \%$ TFA with the proportion of acetonitrile increasing linearly from $0 \%$ to $90 \%$ over 20 min and then decreasing linearly to $0 \%$ over a further $10 \mathrm{~min}$. The product was white powder after lyophilization (retention time, $\left.t_{R}=13.24 \mathrm{~min}\right):{ }^{1} \mathrm{H}$ NMR $\left(400 \mathrm{MHz}, \mathrm{MeOH}-\mathrm{d}_{4}\right) \delta(\mathrm{ppm}): 8.80(\mathrm{~d}, \mathrm{~J}=$ $1.6 \mathrm{~Hz}, 1 \mathrm{H}), 7.35(\mathrm{~d}, \mathrm{~J}=1.2 \mathrm{~Hz}, 1 \mathrm{H}), 4.77\left(\mathrm{AB}_{\mathrm{q}}, \mathrm{J}=5.2 \mathrm{~Hz}, 1 \mathrm{H}\right), 3.40\left(\mathrm{td}, \mathrm{J}_{1}=6.8 \mathrm{~Hz}\right.$, $\left.\mathrm{J}_{2}=2.0 \mathrm{~Hz}, 2 \mathrm{H}\right), 3.30(\mathrm{~m}, 1 \mathrm{H}), 3.13\left(\mathrm{dd}, \mathrm{J}_{1}=15.4 \mathrm{~Hz}, \mathrm{~J}_{2}=8.0 \mathrm{~Hz}, 1 \mathrm{H}\right), 2.43(\mathrm{t}, \mathrm{J}=$ $7.2 \mathrm{~Hz}, 2 \mathrm{H}$ ), 2.18 (t, J = 7.2 Hz, 2H), 1.60 (m, 2H), 1.30 (brs, 24H), 0.92 (t, J = 6.8 Hz, 3H). ESI-MS m/z for $\mathrm{C}_{25} \mathrm{H}_{44} \mathrm{~N}_{4} \mathrm{O}_{4}[\mathrm{M}+1]^{+}$calc. 465.3443, found 465.3443.

Solution and gel formation. $\mathrm{C}_{16}-\beta \mathrm{AH}$ solutions and gels were dissolved in Milli-Q water to the desired concentration and mixed using a vortex mixer, followed by sonication in an ultrasonic bath at $\sim 50^{\circ} \mathrm{C}$ for 5-10 minutes.

Preparation of Vesicles. DPPC MLVs were produced using the thin layer hydration method. ${ }^{23} \mathrm{~A}$ weighted amount of DPPC was dissolved in ethanol in a $100 \mathrm{ml}$ round bottom flask. The ethanol was removed to form a thin DPPC film on the walls of the flask under reduced pressure using a rotary evaporator. Any residual solvent was removed under a stream of $\mathrm{N}_{2}$. A weighed amount of water was then added to the thin DPPC film. The flask was then returned to the rotoevaporator, immersed in a water bath, and vigorously rotated for $\sim 5$ minutes, to reconstitute the lipid film at 50 ${ }^{\circ} \mathrm{C}$. The solution was then put in a flask and vortexed at $50{ }^{\circ} \mathrm{C}$ for five more minutes. Vesicles of DPPC $+C_{16}-\beta A H$ were prepared following a protocol similar to that used for DPPC MLVs, but mixing a convenient amount of $D P P C+C_{16}-\beta A H$ in ethanol.

Pyrene (Pyr) Fluorescence Spectroscopy. Spectra were recorded with a Varian Cary Eclipse Fluorescence Spectrometer with samples in $4 \mathrm{~mm}$ inner width Quartz 
cuvettes. Pyr fluorescence assays were made using a sample containing only Pyr $\left(1.3 \times 10^{-5}\right.$ wt \%), or a set of $\mathrm{C}_{16}-\beta \mathrm{AH}$ solutions dissolved in $1.3 \times 10^{-5} \mathrm{wt} \%$ Pyr. All spectra were measured from 366 to $460 \mathrm{~nm}$, using $\lambda_{\mathrm{ex}}=339 \mathrm{~nm}$.

Circular Dichorism (CD). Spectra were recorded using a Chirascan spectropolarimeter (Applied Photophysics, UK). CD was performed on $\mathrm{C}_{16}-\beta A H$, DPPC or $\mathrm{C}_{16}-\beta \mathrm{AH}+\mathrm{DPPC}$ solutions in water and placed in cover slip cuvettes $(0.01$ or $0.1 \mathrm{~mm}$ thick). Spectra are presented with absorbance $A<2$ at any measured point with a $0.5 \mathrm{~nm}$ step, $1 \mathrm{~nm}$ bandwidth and 1 second collection time per step at $20^{\circ} \mathrm{C}$.

Fourier Transform Infra-red (FTIR) spectroscopy. Spectra were measured on a Nicolet Nexus spectrometer with DTGS detector. FTIR data was measured for $\mathrm{C}_{16^{-}}$ $\beta A H$, DPPC or $\mathrm{C}_{16}-\beta \mathrm{AH}+\mathrm{DPPC}$ solutions in $\mathrm{D}_{2} \mathrm{O}$. Samples were sandwiched between two $\mathrm{CaF}_{2}$ plate windows (spacer $0.0125 \mathrm{~mm}$ ) Spectra were scanned 128 times over the range of $4000-900 \mathrm{~cm}^{-1}$. Data was corrected by baseline subtraction.

Small-Angle X-ray Scattering (SAXS). Experiments were performed on beamline ID02 at the ESRF (Grenoble, France) and on beamline SWING at SOLEIL ${ }^{24}$ (L'Orme des Merisiers, France). At ID02, $0.5 \mathrm{wt} \% \mathrm{C}_{16}-\beta \mathrm{AH}$ samples were placed in a glass capillary mounted in a brass block for temperature control. Micropumping was used to minimise beam damage, by displacing a drop of the sample by $0.01-0.1 \mathrm{~mm}$ for each exposure. The sample-to-detector distance was $1 \mathrm{~m}$, and the X-ray energy was 12.46 keV. The $q=4 \pi \sin \theta / \lambda$ range was calibrated using silver behenate. Data processing (background subtraction, radial averaging) was performed using the software SAXSUtilities. At SWING, a few microlitres of sample (0.03 and 2 wt $\% \mathrm{C}_{16}-\beta A H, 1.5$ $w t \%$ DPPC or $0.03 w t \% \mathrm{C}_{16}-\beta \mathrm{AH}+1.5 \mathrm{wt} \%$ DPPC solutions) were injected at a slow and very reproducible flux into a quartz capillary, placed in front of the X-ray beam. After the sample was injected in the capillary and delivered in front of the X-ray beam, the flow was stopped during the SAXS data acquisition. The wavenumber $q$ range was set to $0.004-0.5 \AA^{-1}$, with $\lambda=1.03 \AA$ (12 keV). The images captured by the 
AVIEX170170 CCD detector were radially averaged and corrected for transmitted intensity and water background using the software Foxtrot.

SAXS Theory. The SAXS intensity from a finite stack of unoriented bilayers can formally be written, within the monodisperse approximation, as:

$$
I(q) \propto\left\langle F^{2}(q) S(q)\right\rangle
$$

where $F^{2}(q)$ is the form factor, and $S(q)$ is the interference or structure factor, which tends to unity for weakly interacting systems.

The form factor was modelled as for a lipid bilayer, based on a sum of Gaussian functions to represent the electron density profile. The details of the model are given elsewhere. ${ }^{25}$ The model assumes an electron density profile comprising Gaussians for the headgroups on either side of the bilayer and another Gaussian for the hydrocarbon chain. Scheme 2 shows a scheme of the electron density distribution along the lamellar normal and illustrates the parameters in the model. The total form factor, is taken as the contributions from the headgroup $F_{H}(q)$ and the hydrocarbon chain $F_{c}(q)$ :

$$
F(q)=2 F_{H}(q)+F_{C}(q)
$$

where

$$
F_{H}(q)=\sqrt{2 \pi} \sigma_{H} \rho_{H} \exp \left(-\frac{\sigma_{H}^{2} q^{2}}{2}\right) \cos \left(q z_{H}\right)
$$

and

$$
F_{C}(q)=\sqrt{2 \pi} \sigma_{C} \rho_{C} \exp \left(-\frac{\sigma_{C}^{2} q^{2}}{2}\right)
$$

The fitting parameters of the model in Equations 3 and 4 are the electron densities of the headgroup $\left(\rho_{H}\right)$, the thickness $z_{H}$, the electron density of the hydrocarbon chains $\left(\rho_{C}\right)$, the standard deviation of the position of the Gaussian peak $z_{H}\left(\sigma_{H}\right)$ and the standard deviation of the position of the Gaussian peak at $z_{C}$ 
$\left(\sigma_{C}\right)$ (Scheme 2). The midpoint of the bilayer is defined as $z=0$. In our model we assumed a Gaussian distribution of inter-headgroup thicknesses $z_{H}$, with an associated degree of polydispersity $\Delta_{H}$.

To model the structure factor, $S(q)$ in Equation 1, we used the modified Caillé theory appropriate for lamellar systems. It corresponds to a multilayer structure influenced by thermal fluctuations. Details of the model are given elsewhere. ${ }^{26-27}$ Briefly, $S(q)$ is described by:

$$
S(q)=N_{d i f f}+\sum_{N_{k}=N-2 \sigma}^{N+2 \sigma} x_{K} S_{K}
$$

where $N$ is the total number of layers within a scattering domain and $N_{\text {diff }}$ accounts for a diffuse background, due to a number of uncorrelated bilayers in $S(q), x_{k}$ is the weight of the structure factor $S_{k},{ }^{28}$ and $S_{k}$ is given by:

$S_{K}=N_{K}+2 \sum_{m=1}^{N_{K}-1}\left(N_{K}-m\right) \cos (m q d) e^{-\left(\frac{2}{2 \pi}\right)^{2} q^{2} \eta \gamma}$

$\gamma$ is the Euler constant in Equation 6, $d$ is the layer spacing, and

$$
\eta=\pi k_{B} T / 2 d^{2}\left(B K_{c}\right)^{1 / 2}
$$

is the Caille parameter which is a measure for the bilayer fluctuations and depends on the bilayer rigidity $K_{c}$ and the bulk modulus of compression $B$.

The fitting parameters in Equations 5-7 are $N, d, \eta$ and $N_{\text {diff. }}$

Congo red assay. A drop of $\mathrm{C}_{16}-\beta \mathrm{AH}$ gel was placed onto a glass microscope slide, and partially stained using a freshly prepared and filtered $1 \mathrm{wt} \%$ Congo red solution in water. The partially stained gel was then placed under a cover slip and observed with the microscope through crossed polarizers, using an Olympus BX41 polarized microscope.

Transmission Electron Microscopy (TEM). Imaging was performed using a Philips CM20 TEM microscope operated at $200 \mathrm{kV}$. Droplets of $\mathrm{C}_{16^{-}} \beta A \mathrm{H}$, DPPC or $\mathrm{C}_{16^{-}}$ $\beta A H+D P P C$ solutions solution were placed on $\mathrm{Cu}$ grids coated with a carbon film 
(Agar Scientific, UK), stained with uranyl acetate (1 wt \%) (Agar Scientific, UK) and dried.

X-ray Diffraction (XRD). X-ray diffraction was performed on stalks prepared by suspending drops of $0.8 \mathrm{wt} \% \mathrm{C}_{16}-\beta \mathrm{AH}$ solutions between the ends of wax-coated capillaries, and allowing them to dry. The stalk was mounted vertically onto the four axis goniometer of a RAXIS IV++ X-ray diffractometer (Rigaku) equipped with a rotating anode generator. The XRD data was collected using a Saturn 992 CCD camera.

DLS. Experiments were performed using an ALV CGS-3 system with 5003 multidigital correlator. The light source was a $20 \mathrm{~mW}$ He-Ne laser, linearly polarized, with $\lambda=633 \mathrm{~nm}$. The scattering angle $\theta=90^{\circ}$ was used for all the experiments.

Samples were loaded into standard $0.5 \mathrm{~cm}$ diameter cylindrical glass cells. DLS experiments measured the intensity correlation function of the radiated-scattered light $g^{(2)}(q, t):^{29}$

$$
g^{2}(q, t)=1+A\left[g^{(1)}(q, t)\right]^{2}
$$

where A accounts for a correction factor depending on the alignment of the instrument, $q=[4 \pi n \sin (\theta / 2)] / \lambda$ is the scattering vector $(\lambda=$ vacuum wavelength of the radiation and $\mathrm{n}=$ refractive index of the medium), $t$ is the delay time, and $\left.g^{(1)(} q, t\right)$ is the electric field correlation function. The program CONTIN can be used to determine the relaxation rate distribution of the $\left\langle\right.$ system $^{30}$ through the modeling of the field correlation function according to:

$$
g^{(1)}(t)=\int_{0}^{\infty} G(\Gamma) \exp (-\Gamma t) d \Gamma
$$

where $G(\Gamma)$ is the relaxation rate distribution. CONTIN allows for the inverse Laplace transform in Equation 9 and provides a tool for calculating the size distribution of the system $\left(G\left(R_{H}\right) ; R_{H}=\right.$ hydrodynamic radius). $R_{H}$ is taken as the radius corresponding to the maximum in $G\left(R_{H}\right)$. 
Cryogenic-Scanning Electron microscopy (cryo-SEM). Imaging was performed using an FEI Quanta 600F instrument. Samples were mounted onto aluminium stubs and frozen in liquid nitrogen slush at approximately $-210^{\circ} \mathrm{C}$. Once frozen, samples were transferred under vacuum to a sample preparation chamber and allowed to equilibrate to the appropriate temperature prior to fracturing. $C_{16}-\beta A H$ solutions were fractured at $-140{ }^{\circ} \mathrm{C}$ and allowed to sublime at $-90^{\circ} \mathrm{C}$ for approximately 10 minutes. DPPC or $\mathrm{C}_{16}-\beta \mathrm{AH}+\mathrm{DPPC}$ solutions were fractured at $-180^{\circ} \mathrm{C}$, to promote vitreous fracturing of individual vesicles, and then allowed to sublime at $-90{ }^{\circ} \mathrm{C}$ for approximately 5 minutes. All samples were allowed to cool to $-140{ }^{\circ} \mathrm{C}$, and then coated with platinum, prior to imaging at $5 \mathrm{kV}$.

Cryogenic-Transmission Electron Microscopy (Cryo-TEM). Experiments were performed at Unilever Research, Colworth (Bedford, UK). Solutions of $C_{16}-\beta A H$, DPPC or $\mathrm{C}_{16}-\beta A H+D P P C$, were blotted and vitrified using a Gatan $\mathrm{Cp} 3$ cryoplunge system. The samples were prepared at a controlled temperature of $22{ }^{\circ} \mathrm{C}$ and at a relative humidity around $90 \%$. A $3-\mu \mathrm{l}$ drop of each solution was placed on a $400-$ mesh copper TEM grid (Agar) covered with a perforated carbon film (plasma treated). The drop was automatically blotted and the sample was plunged into liquid ethane $\left(-183^{\circ} \mathrm{C}\right)$ to form a vitrified specimen, then transferred to liquid nitrogen $\left(-196^{\circ} \mathrm{C}\right)$ for storage. The specimen was examined in a JEOL JEM-2100 electron microscope at $200 \mathrm{kV}$, at temperatures below $-175^{\circ} \mathrm{C}$. Images were recorded digitally on a Gatan UltraScan 1000 cooled CCD camera using DigitalMicrograph (Gatan) in the low-dose imaging mode to minimize beam exposure and electron-beam radiation damage.

\section{Results and Discussion}

\section{Self assembly of $C_{16}-\beta A H$ in water}

In the following we will describe the self-assembly of $\mathrm{C}_{16}-\beta \mathrm{AH}$ in pure water. In order to highlight the secondary structure formation in $\mathrm{C}_{16}-\beta \mathrm{AH}$ solutions, selected 
results obtained for $\mathrm{C}_{16}-\mathrm{BAH}$ solutions will be compared with those previously obtained by us for Fmoc- $\beta \mathrm{AH}$ and $\beta \mathrm{AH}$ solutions. ${ }^{15}$

Figure $\mathrm{S} 1$ (Supporting Information) shows that $\mathrm{C}_{16}-\beta A \mathrm{H}$ dissolves in water as a solution for concentrations lower than $0.7 \mathrm{wt} \%$ peptide while it forms a self standing gel at higher concentration. The $\mathrm{pH}$ of the sample continuously drops from 6.5 to 1.5 when the concentration of the sample increases from 0.003 to 2 wt $\% C_{16}-\beta A H$ (inset Figure S1, Supporting Information). The isoelectric point for $\mathrm{C}_{16}-\beta A H$ is 7.85 , calculated using web-based software. ${ }^{37}$ Since solutions of the PA have $\mathrm{pH}$ 6.5-4. while self standing gels have $\mathrm{pH} \sim 1.5$, the molecule will carry positive charge under $\underline{\text { these conditions. }}$

$\mathrm{C}_{16}-\beta \mathrm{AH}$ gel point is 0.7 wt\% PA (inset Figure $\mathrm{S} 1$ ), lower than Fmoc- $\beta \mathrm{AH}$ gel point ( 1 wt \% PA). ${ }^{15}$ The octanol-water partition coefficient, $\log P=3.971$, calculated for $\mathrm{C}_{16}-\beta A H$ using web-based software, ${ }^{31}$ quantifies the hydrophobicity of $C_{16}-\beta A H$. Addition of $\mathrm{C}_{16}$ leads to a substantial increase in hydrophobicity $(\log P=-3.7$ for $\beta \mathrm{AH}$ and $\log P=0.483$ for Fmoc- $\beta A H)^{15}$ and allows for gelation at concentrations lower than the Fmoc- $\beta \mathrm{AH}$ gel point.

Pyr fluorescence studies were performed in order to determine the critical aggregate concentration (cac) for $\mathrm{C}_{16}-\beta \mathrm{AH}$ in water. This technique is routinely used to determine the critical micellar concentration for amphiphiles. ${ }^{32-35}$ It is based is the analysis of the fluorescence intensity of the $0-0$ band at $\lambda \sim 373 \mathrm{~nm}$, denoted $\mathrm{I}_{1}$, and the fluorescence intensity of the ratio $\mathrm{I}_{1} / \mathrm{I}_{3}\left(\mathrm{I}_{3}\right.$ : third principal vibronic band at $\lambda \sim 383$ $\mathrm{nm}) .{ }^{36}$ We have used Pyr fluorescence in the past to determine the cac Fmoc- $\beta A H .{ }^{15}$ The inset in Figure 1 shows some representative examples of the fluorescence emission spectra measured for samples containing $\left(0-6 \times 10^{-3}\right)$ wt $\% \mathrm{C}_{16^{-}}$ $\beta \mathrm{AH}$ and $1.3 \times 10^{-5}$ wt $\%$ Pyr. The emission spectrum of Pyr $\left(\lambda_{\mathrm{ex}}=339 \mathrm{~nm}\right)$ is 
characterized by the strong fluorescence of the $0-0$ band $(\lambda \sim 373 \mathrm{~nm})$, denoted as $\mathrm{I}_{1}$ ${ }^{36}$ (inset Figure 1). The results show an increase of the fluorescence intensity upon increasing the $\mathrm{C}_{16}-\mathrm{BAH}$ concentration with a fixed concentration of Pyr. This increase in intensity reflects the increase of the lifetime of the excited state of Pyr. ${ }^{33}$ Pyr in water has only a very small absorption at $339 \mathrm{~nm}$, which increases substantially upon transfer to a less polar domain. ${ }^{33}$ Therefore, the enhancement of the intensity with increasing $\mathrm{C}_{16}-\beta \mathrm{AH}$ concentration is correlated to the formation of aggregates and the insertion of the Pyr probe within the hydrophobic cores of those aggregates. This idea is supported by the measurement of the $\mathrm{I}_{1} / \mathrm{I}_{3}$ fraction discussed below.

Below the cac, Pyr is free in the solution and the quantum yield is high, leading to a high $\mathrm{I}_{1} / \mathrm{I}_{3}$ ratio (Figure 1 ). Above the cac, Pyr is selectively sequestered within the aggregates core and the $\mathrm{I}_{1} / \mathrm{I}_{3}$ ratio is reduced. Our results indicate a cac value of $2 \times 10^{-3}$ wt $\% \mathrm{C}_{16}-\beta \mathrm{AH}$. This value is significantly lower than $c a c=7 \times 10^{-2} \mathrm{wt} \%$ measured for $\mathrm{Fmoc}-\beta A \mathrm{H}$, proving that the $\mathrm{C}_{16}$-unit drives self assembly more efficiently than the Fmoc-unit.

The isoelectric point for $G_{16}-\beta A H$ is 7.85 , calculated using web-based software ${ }^{37}$. According to the data in Figure S1, $C_{16}-\beta A H$ dissolved in water presents one positive charge for concentrations higher or equal to the cac. Solutions of the PA have pH 6.5-4, while self standing gels have $\mathrm{pH} \sim$ 1.5. ADD HERE A PARAGRAPH ABOUT SPECULATION OF DEPENDENCE OF pH ON SELF-ASSEMBLY.

The secondary structure in solution was investigated by CD. Figure S2 (Supporting Information) shows the CD spectra obtained for 0.05 wt $\% \mathrm{C}_{16}-\beta \mathrm{AH}$. The $\mathrm{CD}$ spectrum for 0.05 wt $\% \mathrm{C}_{16}-\beta \mathrm{AH}$ is characterized by a wide positive band at $\sim 222 \mathrm{~nm}$ (Figure S2). It is possible that the positive band at $222 \mathrm{~nm}$ arise from stacking interactions of the aromatic histidine units, because CD spectra with peaks Comment [IW3]: You have said you removed the spectrum for $0.8 \%$ but it's still in this region have been reported for Fmoc-tyrosine derivatives, ${ }^{38-39}$ and FmoGpeptides containing $R, G$ and $D$ residues. ${ }^{40}$ 
since the CD spectra for random coil poly-L-histidine is characterized by a maximum at $222 \mathrm{~nm} .{ }^{41-43}$ The CD spectra do not provide information about the selfassembly of $\mathrm{C}_{16}=\mathrm{\beta AH}$ into structures with highly hydrophobic cores capable of hosting the Pyr probe, as depicted in Figure 1. Therefore, the secondary structure of $\mathrm{C}_{16}$ $\beta A H$ aggregates was further studied by FTIR at for 0.8 and 2 wt $\% \mathrm{C}_{16}-\beta A \mathrm{H}$ solutions. Figure 2a corresponds to the amide I region of the FTIR spectra. The significant peaks are listed in Table 1 and compared to those previously measured by us for $\beta A H$ and Fmoc- $\beta A H .{ }^{15}$ The data in Figure $2 a$ shows that $C_{16}-\beta A H$ appears to self assemble into $\beta$-sheets at 0.8 and 2 wt\% (Table 1). In addition to the FTIR bands previously measured for Fmoc- $\beta A H$ (Figure $2 \mathrm{a}$, Table 1), the peak at $1718 \mathrm{~cm}^{-1}$, probably associated to the $\mathrm{C}=\mathrm{O}$ vibration of the $\mathrm{C}_{16}$-chain, ${ }^{41}$ appears to be exclusively associated to $\mathrm{C}_{16}-\beta \mathrm{AH}$ concentration, as it develops upon increasing $\mathrm{PA}$ content and it is not present for $\beta \mathrm{AH}$ or Fmoc- $\beta \mathrm{AH}$ (Table 1).

Other regions of the FTIR spectra provide information on the lipid chain ordering present in $\mathrm{C}_{16}-\beta \mathrm{AH}$ but obviously absent for $\beta \mathrm{AH}$ or Fmoc- $\beta \mathrm{AH}$. Figure $2 \mathrm{~b}$ $\left(\mathrm{CH}_{2}\right.$ stretch region $\left.2850-2950 \mathrm{~cm}^{-1}\right)$ shows peaks in the spectra at 2952, 2917 and $2849 \mathrm{~cm}^{-1}$, which arise from stretching vibrations of the $\mathrm{CH}_{2}$ groups. In the range $1400-1500 \mathrm{~cm}^{-1}$, the FTIR spectra for all samples display a peak at $1462 \mathrm{~cm}^{-1}$ corresponding to the $\mathrm{CH}_{2} / \mathrm{CH}_{3}$ scissoring band ${ }^{42-44}$ (results not shown).

The results from FTIR spectroscopy experiments show that $\mathrm{C}_{16}-\beta A H$ self assembles in solution forming $\beta$-sheet structures, held together by the amide bonds in the $\beta \mathrm{AH}$ block, while the there is also stacking of histidine rings-are stacked within some domains in the sample. The lipid chains presumably associate via hydrophobic interaction.

Further evidence for amyloid formation by $\mathrm{C}_{16}-\beta \mathrm{AH}$ was provided by Congo red dye labeling experiments. Congo red staining leading to birefringence is a characteristic of amyloid formation ${ }^{45}$ Figure S3 (Supporting Information) shows POM 
images obtained for a pure 2 wt \% $\mathrm{C}_{16}-\beta \mathrm{AH}$ gel (Figure S3a) and the same gel partially stained with Congo red (Figure S3b). The bright grey birefringence in Figure S3a denotes a supramolecular ordered structure in the sample. Figure S3b shows the regions of light green birefringence caused by the Congo red binding to the amyloid fibrils.

SAXS and XRD were used to characterize the long range order of $\mathrm{C}_{16}-\beta A H$ in solution. Figure $3 a$ shows the SAXS profile measured for 0.5 and 2 wt $\% C_{16}-\beta A H$. The XRD profile measured for a stalk dried from a $0.8 \% \mathrm{C}_{16}-\beta A H$ solution is displayed in Figure 3b.

The SAXS for $0.5 \mathrm{wt} \%$ peptide (Figure 3a) shows three characteristic peaks at $q$ radii 1:1.95:2.9 (principal peak wavenumber $q_{0}=0.1348 \AA^{-1}$ ) which correspond to a layered structure with a period of $d=46.6 \AA^{46}{ }^{46}$ This indicates a bilayer structure of the PA when the length of a $C_{16}$ chain $(16 \AA)$ plus $\beta A H$ headgroup $(7 \AA)$ is considered. In contrast to the data for the 0.5 wt $\%$ PA solution, the intensity profile for 2 wt\% $\mathrm{C}_{16}-\beta \mathrm{AH}$ lacks defined Bragg peaks. Instead, it is characterized by a broad peak centred at $q=0.1696 \AA^{-1}$, which is mainly due to the form factor of the layered nanotape structure, as discussed shortly. In addition, both SAXS for 0.5 and 2 wt\% peptide show a peak at $q=0.3034 \AA^{-1}(d=20.7 \AA)$.

The XRD profile for a stalk dried from a solution of $\mathrm{C}_{16}-\beta A H$ (Figure $3 b$ ) is characterized by two peaks with ratios of peak position $1: 2\left(q_{0}=0.1784 \AA^{-1}\right)$ which correspond to a layered structure with a period of $d=35.2 \AA{ }^{46}$ Figure $3 b$ shows a peak at $q=0.3049 \AA^{-1}(d=20.6 \AA)$, similar to that displayed in Figure 3a. The peaks at $4.2 \AA$ in Figure $3 \mathrm{~b}$ correspond to the lateral distance between $\mathrm{C}_{16}$ chains.

The SAXS curves in Figure $3 a$ were modelled according to Equations 1-7, using the software SASfit. ${ }^{47}$ The fitted SAXS curves are displayed in Figure 4, while the obtained parameters are listed in Table 2. 
According to the results in Table 2, the number of layers in the stack, $N$, within the nanotapes decreases when the PA concentration increases from 0.5 to 2 wt\%, from $N=7$ to $N=2-3$ (the fit shown in Figure $4 \mathrm{~b}$ is for $\mathrm{N}=3$, but similar quality fits could be obtained for $N=2$ ) corresponding to the loss of Bragg peaks on increasing concentration. From the fit parameters, it is possible to estimate a total layer thickness $l \sim\left(2 z_{H}+2 \sigma_{H}\right)$ with an uncertainty $\Delta_{H}$. For 0.5 wt\% $\mathrm{C}_{16}-\beta A H$ (Table 2$)$, the value of $l$ is less than $d=46.6 \AA$ as expected for a hydrated multilayer stack (i.e. $d=l$ $+l_{w}$, where $l_{w}$ is the thickness of the water layer). For the 2 wt $\% \mathrm{C}_{16}-\beta A H$ solution, the period is reduced to $d=35.2 \AA$. The estimated value of $l$ is similar to $d$, within the experimental error, suggesting a dehydrated structure.

Based on the analysis of the SAXS data for the PA at the two concentrations, model layer structures shown in Figure 5 are put forward. The 0.5 wt $\%$ solution comprises mainly hydrated bilayers with a spacing of $46 \AA$ (Figure 5a). It is proposed that these structures coexist with monolayers with a thickness of $21 \AA$. This thickness is consistent with the up-down arrangement of PA molecules shown in Figure 5b. A coexistence of bilayers and thicker structures with occasional monolayers was observed by us recently for the PA $\mathrm{C}_{16}$ KTTKS. $^{48}$ At higher concentration, the $\mathrm{C}_{16^{-}}$ $\beta \mathrm{AH}$ tapes undergo dehydration leading to a $35 \AA$ bilayer thickness, which is consistent with the estimated length of the molecules stacked in a bilayer allowing for some disorder in the lipid chains as shown in Figure 5c.

It is proposed that the concentration-induced reduction in observed layer spacing for $\mathrm{C}_{16}-\beta \mathrm{AH}$ results from dehydration of the bilayers. This may be facilitated by screening of electrostatic interactions on the peptide headgroups (due to increased counterion concentration) which reduces the charge on the surface of the layers, leading to a 'coagulation' or coalescence transition, due to the attractive van the Waals interactions, analogous to phenomena in colloidal dispersions described by the DLVO theory. 
The self-assembled structure formed by $\mathrm{C}_{16}-\beta \mathrm{AH}$ was further investigated at the nanoscale for 0.05 and 1 wt $\% C_{16}-\beta A H$. TEM images for 0.05 wt $\% C_{16}-\beta A H$ revealed extended tape structures (Figure 6a) with a persistence length of $(4.4 \pm 1.3)$ $\mu \mathrm{m}$ and $(82.9 \pm 18) \mathrm{nm}$ thick. Increasing the concentration to $1 \mathrm{wt} \% \mathrm{C}_{16}-\beta A H$, TEM shows the formation of twisted thin fibrils $(16.4 \pm 3) \mathrm{nm}$ thin (Figure $6 \mathrm{~b}$ ) or rigid tapes (101.4 \pm 16.9$) \mathrm{nm}$ thick (Figure $6 \mathrm{c}$ ). Our previous TEM study on Fmoc- $\beta$ AH solutions, showed long twisted fibres $(6.9 \pm 0.8) \mathrm{nm}$ thick. ${ }^{15}$ It is evident that the formation of $\mathrm{C}_{16^{-}}$ $\beta A H$ wide tapes is a consequence of the self assembly of the PA into layered structures (Figure 5).

Cryo-SEM images obtained for 1 wt $\% \mathrm{C}_{16}-\beta A H$ sample (Figure S4, Supporting Information) confirm the results shown in Figure 6. The sample self assembles in two different species, i.e., $(129 \pm 18) \mathrm{nm}$ thick tapes and very thin twisted fibres. Because of the process involved in the cryo-SEM sample preparation, the thin fibres are clustered together (Figure S4). The cryo-SEM resolution did not allow for an accurate determination of the thin fibril thickness in Figure S4, however it could be estimated to be of the order of tens of $\mathrm{nm}$.

\section{Study of DPPC and $D P P C / C_{16}-\beta A H$ solutions.}

In the following we will discuss the formation of DPPC vesicles containing $\mathrm{C}_{16}-\beta \mathrm{AH}$. Vesicles were produced in solutions containing 1.5 wt\% DPPC and 1.5 wt\% DPPC+0.03 wt\% $\mathrm{C}_{16}-\beta \mathrm{AH}$, following the protocol described in the Experimental Section. We chose to study solutions containing 0.03 wt $\% \mathrm{C}_{16} \beta \mathrm{AH}$ because although this concentration is above the cac, it is low enough for the PA to be potentially incorporated into the DPPC vesicles without changing its structural parameters.

Self-assembly was first examined by TEM for 0.03 wt\% $\mathrm{C}_{16}-\beta A \mathrm{H}$ solution, and then vesicles prepared with $1.5 \mathrm{wt} \% \mathrm{DPPC}$ or $1.5 \mathrm{wt} \% \mathrm{DPPC}+0.03 \mathrm{wt} \% \mathrm{C}_{16}-\beta \mathrm{AH}$ were imaged. 
Figure 7a shows a TEM image of peptide tapes formed at $0.03 \mathrm{wt} \% \mathrm{C}_{16}-\beta \mathrm{AH}$, similar to those already discussed in Figure 6.

TEM image in Figure $7 \mathrm{~b}$ shows the formation of collapsed vesicles in a 1.5 wt\% solution of DPPC, denoting that DPPC vesicles are not robust enough to be dried onto a TEM grid without collapsing. Indeed, it has already been reported that MLVs might be affected by the high vacuum and staining process required by TEM. ${ }^{49}$ However, DPPC vesicles were nearly spherical in shape, with three different size distributions centred on $2.6 \mu \mathrm{m}, 215 \mathrm{~nm}$ and $72 \mathrm{~nm}$ (Figure $7 \mathrm{~b}$ ).

The preparation of $\mathrm{DPPC} / \mathrm{C}_{16}-\beta \mathrm{AH}$ mixed vesicles resulted in three size distributions, similarly to DPPC vesicles (Figure 7c). Figure $7 \mathrm{c}$ is characterized by the absence of PA tapes, but the formation of nearly spherical vesicles with size distributions centred on $2.3 \mu \mathrm{m}, 630 \mathrm{~nm}$ and $87 \mathrm{~nm}$.

The formation of DPPC/PA vesicles, was further studied by cryo-SEM. Figure $7 d, 7 e$ and $7 f$ respectively show representative images for 0.03 wt $\% C_{16}-\beta A H, 1.5$ $w t \%$ DPPC and $1.5 w t \%$ DPPC $+0.03 w t \% \mathrm{C}_{16}-\beta A H$.

SEM images in Figure $7 d$ show a network structure for $C_{16}-\beta A H$, comprising

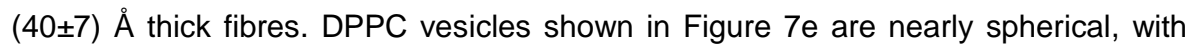
size distributions centred on $7.2 \mu \mathrm{m}$ and $551 \mathrm{~nm}$. Samples containing $\mathrm{DPPC}+\mathrm{C}_{16^{-}}$ $\beta \mathrm{AH}$ mixtures (Figures $7 \mathrm{f}$ ) did not show the formation of fibril networks similar to those shown in Figure 7d, but instead nearly spherical vesicles with size distributions centred on $5.4 \mu \mathrm{m}$ and $508 \mathrm{~nm}$.

TEM and cryo-SEM only show the formation of vesicles for the DPPC $+C_{16^{-}}$ $\beta A H$ system with sizes similar to pure DPPC vesicles, suggesting the incorporation of the PA within the DPPC vesicles. TEM vesicle sizes, affected by sample preparation protocol and high vacuum, are smaller than cryo-SEM vesicle sizes. In order to evaluate the effect of the sample preparation protocol, cryo-TEM was used as an alternative imaging method to study $D P P C$ and $D P P C+C_{16}-\beta A H$ solutions. 
Figure $8 \mathrm{a}, 8 \mathrm{~b}$ and $8 \mathrm{c}$ show cryo-TEM images obtained for $0.03 \mathrm{wt} \% \mathrm{C}_{16}-\beta \mathrm{AH}$, $1.5 \mathrm{wt} \%$ DPPC and $1.5 \mathrm{wt} \%$ DPPC+ $0.03 \mathrm{wt} \% \mathrm{C}_{16}-\beta \mathrm{AH}$ respectively.

Figure $8 \mathrm{a}$ shows the presence of $(146.3 \pm 30.2) \mathrm{nm}$ thick tapes for $0.03 \mathrm{wt} \%$ $\mathrm{C}_{16}-\beta \mathrm{AH}$. 1.5 wt\% DPPC solutions (Figure $8 \mathrm{~b}$ ) contained vesicles with two size distributions centred on $540 \mathrm{~nm}$ and $90 \mathrm{~nm}$. Similarly, $1.5 \mathrm{wt} \% \mathrm{DPPC}+0.03 \mathrm{wt} \% \mathrm{C}_{16^{-}}$ $\beta \mathrm{AH}$ solutions showed the formation of vesicles $550 \mathrm{~nm}$ and $80 \mathrm{~nm}$ in size (Figure $8 c)$. Some of the vesicle shapes in Figures $8 b-c$ are not smoothly curved but have segments of zero curvature. This effect has been previously observed in DPPC vesicles and was ascribed to the freezing process used in cryo-TEM ${ }^{50}$ Nevertheless, data in Figures 8b,c show a decrease in the vesicle wall thickness from $13 \mathrm{~nm}$ for DPPC to $7 \mathrm{~nm}$ for $\mathrm{DPPC}+\mathrm{C}_{16}-\beta \mathrm{AH}$. The vesicles wall thickness reduction will be discussed below in relation to SAXS results.

Dynamic light scatteringts experiments were performed on $1.5 \mathrm{wt} \%$ $\mathrm{DPPC}+0.03 \mathrm{wt} \% \mathrm{C}_{16}-\beta \mathrm{AH}$ sample and the corresponding control solutions. The resulting $G\left(R_{H}\right)$ distributions provide two main $R_{H}$ values for each solution (Figure 9f $=$. These values are $R_{H 1}=109 \mathrm{~nm}$ and $R_{H 2}=436 \mathrm{~nm}$ for $0.03 \mathrm{wt} \% \mathrm{C}_{16}-\beta \mathrm{AH}$. According to Figure 9, $R_{H l}=352 \mathrm{~nm}$ and $R_{H I}=2.6 \mu \mathrm{m}$ for 1.5 wt\% DPPC while $R_{H l}=$ $544 \mathrm{~nm}$ and $R_{H l}=3.9 \mu \mathrm{m}$ for $1.5 \mathrm{wt} \% \mathrm{DPPC}+0.03 \mathrm{wt} \% \mathrm{C}_{16}-\beta \mathrm{AH}$. The increase in vesicle size for the mixed system registered by DLS was probably hindered-obscured in TEM and SEM results-due to the sample preparation methods.

Cumulative data obtained by results in Figure 7-9 show that both DPPC and DPPC $+\mathrm{C}_{16}-\beta A H$ solutions only form vesicles, with wide size distributions ranging form $\sim 0.07 \mu \mathrm{m}$ to $7.2 \mu \mathrm{m}$. The hydrodynamic radius of DPPC vesicles increases while the thickness of the DPPC vesicles wall is reduced upon addition of $\mathrm{C}_{16}-\beta A H$. In addition. FTIR experiments on 1.5 wt\% DPPC+0.03 wt\% $\mathrm{C}_{16}-\beta A H$ and the corresponding controls, show that the $\beta$-sheet structure present for $0.03 \mathrm{wt} \% \mathrm{C}_{16^{-}}$ $\beta \mathrm{AH}$ is not present in the mixed system (Figure S5, Supporting Information), in good 
agreement with the absence of tapes in Figures $7 \mathrm{c}, \mathrm{f}$ and Figure 8c. Figure S5 shows that at low wave numbers, there is only one FTIR absorption band at $1737 \mathrm{~cm}^{-1}$, associated to the $\mathrm{C}=\mathrm{O}$ vibration of the $\mathrm{C}_{16}$ chain. ${ }^{41}$

The information related to the vesicles wall structure is constrained by the resolution of the microscopy techniques used in Figures 7-8. Therefore, SAXS was used to get an insight into the influence of $\mathrm{C}_{16}-\beta \mathrm{AH}$ addition to the walls of DPPC vesicles. Figure 9 shows the SAXS measured for $1.5 \mathrm{wt} \%$ DPPC, $0.3 \mathrm{wt} \% \mathrm{C}_{16}-\beta A H$ and $1.5 \mathrm{wt} \% \mathrm{DPPC}+0.3 \mathrm{wt} \% \mathrm{C}_{16}-\beta \mathrm{AH}$.

The SAXS data for DPPC has been collected at $20{ }^{\circ} \mathrm{C}$ which corresponds to the $L_{\beta^{\prime}}$ gel phase of the lipid. ${ }^{51}$ Peaks 1,3 and 4 measured for $1.5 \mathrm{wt} \%$ DPPC (Figure 10) can be indexed as the $1^{\text {st }}, 2^{\text {nd }}$ and $3^{\text {rd }}$ order respectively of a $64.3 \AA$ layer spacing, which is consistent with the values reported in the literature for the DPPC $L_{\beta}$, gel phase..$^{52-53}$ The SAXS measured for $0.03 \mathrm{wt} \% \mathrm{C}_{16}-\beta A H$ shows a peak centred on $21.1 \AA$, in agreement with the data in Figure 3a. While SAXS confirmed the multilamellar nature of pure DPPC vesicles, the absence of Bragg reflections in the SAXS curve for $1.5 \mathrm{wt} \% \mathrm{DPPC}+0.3 \mathrm{wt} \% \mathrm{C}_{16}-\beta \mathrm{AH}$ denotes a low internal order at the vesicles wall.

The SAXS curves for $1.5 \mathrm{wt} \%$ DPPC and $1.5 \mathrm{wt} \%$ DPPC $+0.3 \mathrm{wt} \% \mathrm{C}_{16}-\beta A H$ were modelled using Equations 1-7. The results are displayed in Figure 10, while the extracted parameters are listed in Table 2.

The parameter $2 z_{H}=40.3 \AA$ obtained for $1.5 \mathrm{wt} \%$ DPPC (Figure 11a), is in good agreement with the $44.2 \AA$ reported by $\mathrm{Nagle}^{51}$ for the headgroup peak-peak distance in the electron density profile for DPPC at $20^{\circ} \mathrm{C}$.

The SAXS data shows that addition of 0.03 wt $\% \mathrm{C}_{16}-\beta A H$ produces unilamellar vesicles, since the data in Figure $10 \mathrm{~b}$ are fitted to a model comprising only the bilayer form factor. The SAXS curve for this system can be modelled with $z_{H}$ 
and $\sigma_{H}$ values similar to the values for DPPC suggesting that the DPPC still forms the majority component in the unilamellar vesicle walls (Figure 11b).

A transition for MLVs to unilamelar vesicles was suggested by cryo-TEM results above, which denoted a reduction in the vesicle wall thickness upon addition of $\mathrm{C}_{16}-\beta A H$ to the DPPC system (Figures $8 \mathrm{~b}-\mathrm{c}$ ).

It has already been reported that for dimyristoylphosphatidylcholine/ dimyristoylphosphatidylserine mixtures, charge repulsion between headgroups tends to destabilize multilamellar vesicles resulting into unilamellar vesicles. ${ }^{54}$ The unilamellar structure of $\mathrm{DPPC} / \mathrm{C}_{16}-\beta A H$ vesicles might be a consequence of electrostatic interactions. While DPPC is a zwitterionic molecule in solution, the imidazole moiety of $\mathrm{C}_{16}-\beta \mathrm{AH}$ has an effective charge of -1 in solution. ${ }^{8}$ It is proposed that addition of $\mathrm{C}_{16}-\beta \mathrm{AH}$ decorates DPPC bilayers, allowing thinning into a unilamellar structure due to charge repulsion between the headgroups.

\section{Conclusion}

In a previous paper we proved that Fmoc- $\beta A H$ self assembles into fibrils such that the fibril core contains the $\beta \mathrm{AH}$ moiety while a fraction of the Fmoc unit is exposed to the aqueous environment. ${ }^{15}$ It was argued that although the Fmoc unit is highly hydrophobic, the exposure of this unit to water probably drives Fmoc- $\beta$ AH self assembly into fibrils.

Here, we prove that $C_{16}$ drives the self assembly of $C_{16}-\beta A H$ into nanotapes because of excluded volume constraints imposed by the $C_{16}$ chain structure. $C_{16}-\beta A H$ nanotapes with a bilayer internal structure coexist with $\mathrm{C}_{16}-\beta A H$ nanotapes with a monolayer internal structure in solution. $\mathrm{C}_{16}-\beta A H$ monolayer nanotapes consist of PA molecules packed with an alternating up-down arrangement. Within the bilayer nanotapes, $\mathrm{C}_{16}-\beta \mathrm{AH}$ adopts a single orientation allowing for the formation of $\beta$-sheets 
strands between neighbouring headgroups. Bilayer nanotapes become dehydrated as PA concentration increases.

We explored the influence of DPPC vesicles on the self-assembly of a model peptide amphiphile, and vice-versa. We proved that the addition of the PA to DPPC MLVs does not affect the overall size of the vesicle, but induces a transition to welldefined unilamellar vesicles. $C_{16}-\beta A H$ does not self-assemble into fibres in the presence of DPPC. It is probable that the PA decorates either side of the DPPC bilayers, adding a net negative charge to the DPPC bilayers surface and driving a multilamellar to unilamellar transition via electrostatic repulsion of the headgroups.

Acknowledgements This work was supported by EPSRC grants EP/F048114/1 and EP/G026203/1. We are grateful to T. Narayaran for support in the beamline ID02 (ESRF) during SAXS experiments (project code SC3235) and to J. Perez for his help during SAXS experiments at SOLEIL (project code 20110562) 
Table 1: Wavenumbers $\left(\mathrm{cm}^{-1}\right)$ and assignments of the FTIR bands of $\mathrm{C}_{16}-\beta A H, \beta A H$, and Fmoc- $\beta A H$.

\begin{tabular}{|c|c|c|l|}
\hline $\begin{array}{c}0.8 \mathrm{wt} \% \mathrm{C}_{16}-\beta \mathrm{AH} \\
{\left[\mathrm{cm}^{-1}\right]}\end{array}$ & $\begin{array}{c}1 \mathrm{wt} \% \beta \mathrm{AH}^{15} \\
{\left[\mathrm{~cm}^{-1}\right]}\end{array}$ & $\begin{array}{c}1 \mathrm{wt} \% \mathrm{Fmoc}^{-1} \beta \mathrm{AH}{ }^{15} \\
{\left[\mathrm{~cm}^{-1}\right]}\end{array}$ & Assignments \\
\hline 1718 & & 1684 & $\beta$-sheet \\
\hline & & $1670-58$ \\
\hline 1675 & & 1636 & TFA counterions $^{59-60}$ \\
\hline 1629 & 1594 & & $\beta$-sheet $^{55-58}$ \\
\hline 1605 & & 1591 & $\mathrm{NH}_{3}{ }^{+}$group $^{61-62}$ \\
\hline 1586 & & $\mathrm{NH}_{4}{ }^{+}$ions $^{15}$ \\
\hline
\end{tabular}


Table 2. SAXS parameters extracted from the fittings of the experimental data shown in Figure 4 and Figure 10

\begin{tabular}{|c|c|c|c|c|c|c|c|c|c|}
\hline Sample & $\begin{array}{r}2 z_{H} \\
{[\AA \AA A]}\end{array}$ & $\begin{array}{l}\Delta_{H} \\
{[\AA]}\end{array}$ & $\begin{array}{c}\rho_{H} \\
\text { [rel. } \\
\text { units] }\end{array}$ & $\begin{array}{l}\sigma_{H} \\
[\AA]]\end{array}$ & $\begin{array}{c}\rho_{C} \\
\text { [rel. } \\
\text { units] }\end{array}$ & $\begin{array}{l}\sigma_{C} \\
{[\AA]}\end{array}$ & $N$ & $\left.\begin{array}{c}d \\
{[\AA ̊}\end{array}\right]$ & $\eta$ \\
\hline $0.5 w t \% C_{16}-\beta A H$ & 33.5 & 3.6 & $1.3 e-6$ & 3.6 & $-6.2 e-8$ & 3.3 & 6.6 & 46.5 & 0.12 \\
\hline $2 \mathrm{wt} \% \mathrm{C}_{16}-\beta A \mathrm{H}$ & 31.8 & 5.8 & $4.9 e-8$ & 4.9 & $-6.2 e-9$ & 2.2 & 3 & 35.3 & 0.2 \\
\hline $1.5 \mathrm{wt} \%$ DPPC & 40.3 & 13.4 & $2.5 e-8$ & 3 & $-2.4 e-8$ & 3 & 7.9 & 63.7 & 0.06 \\
\hline $\begin{array}{c}1.5 w t \% \text { DPPC+ } \\
0.03 w t \% \mathrm{C}_{16}-\mathrm{BAH}\end{array}$ & 42.5 & 5 & $1.9 e-7$ & 3 & $-1.3 e-7$ & 3.7 & - & - & - \\
\hline
\end{tabular}




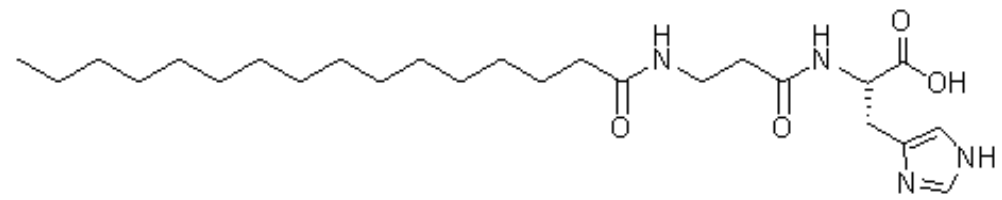

Scheme 1 - Chemical structure of $\mathrm{C}_{16}-\beta A H$ 


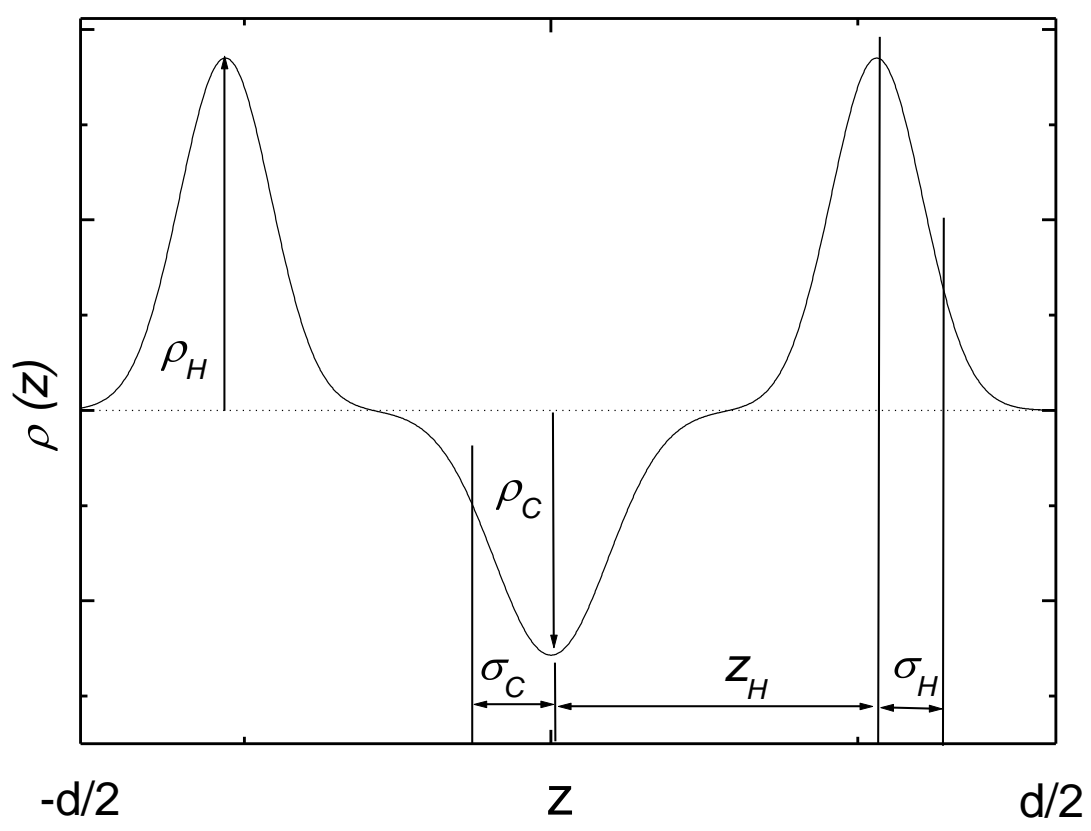


Scheme 2. Gaussian model of the electron density profile used to describe $F(q)$ in Equation 2. 


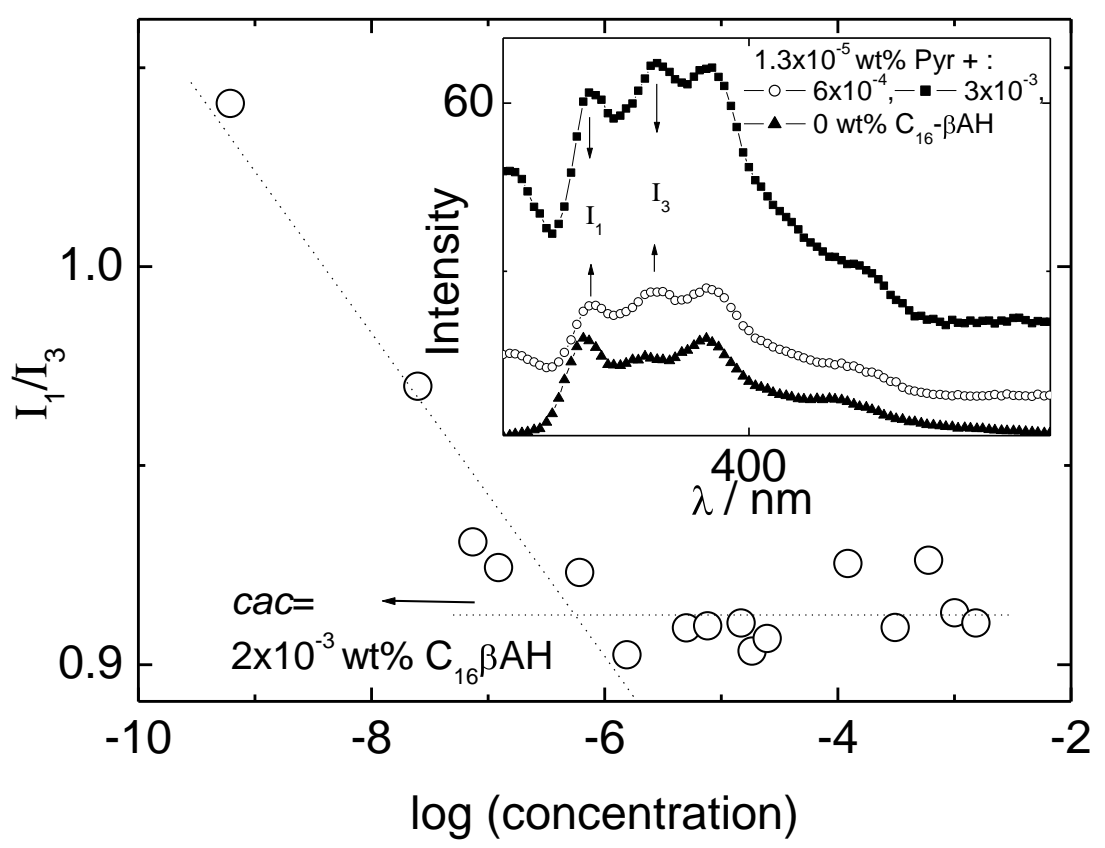

Figure 1. Determination of cac from the dependence of $I_{1} / I_{3}$ on $C_{16}-\beta A H$ concentration for samples containing $1.3 \times 10^{-3}$ wt\% Pyrene. 

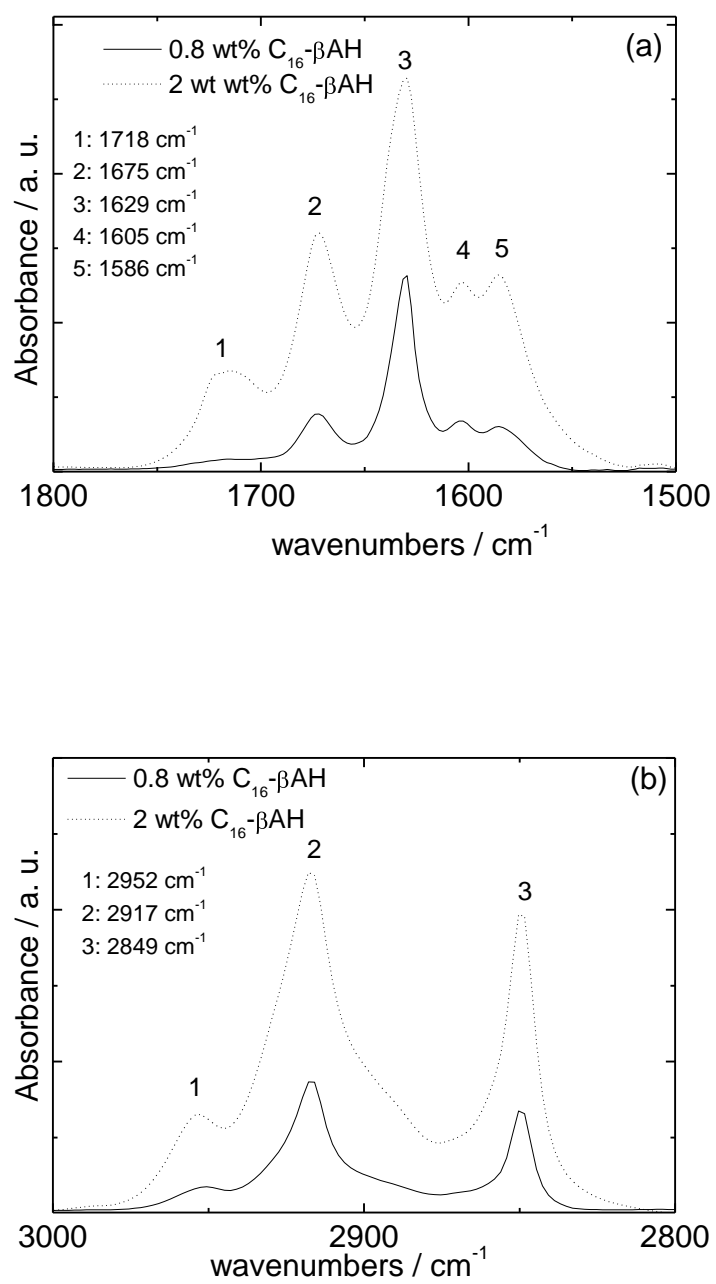

Figure 2. (a-b) FTIR data measured for 0.8 and 2 wt $\% C_{16}-\beta A H$. 

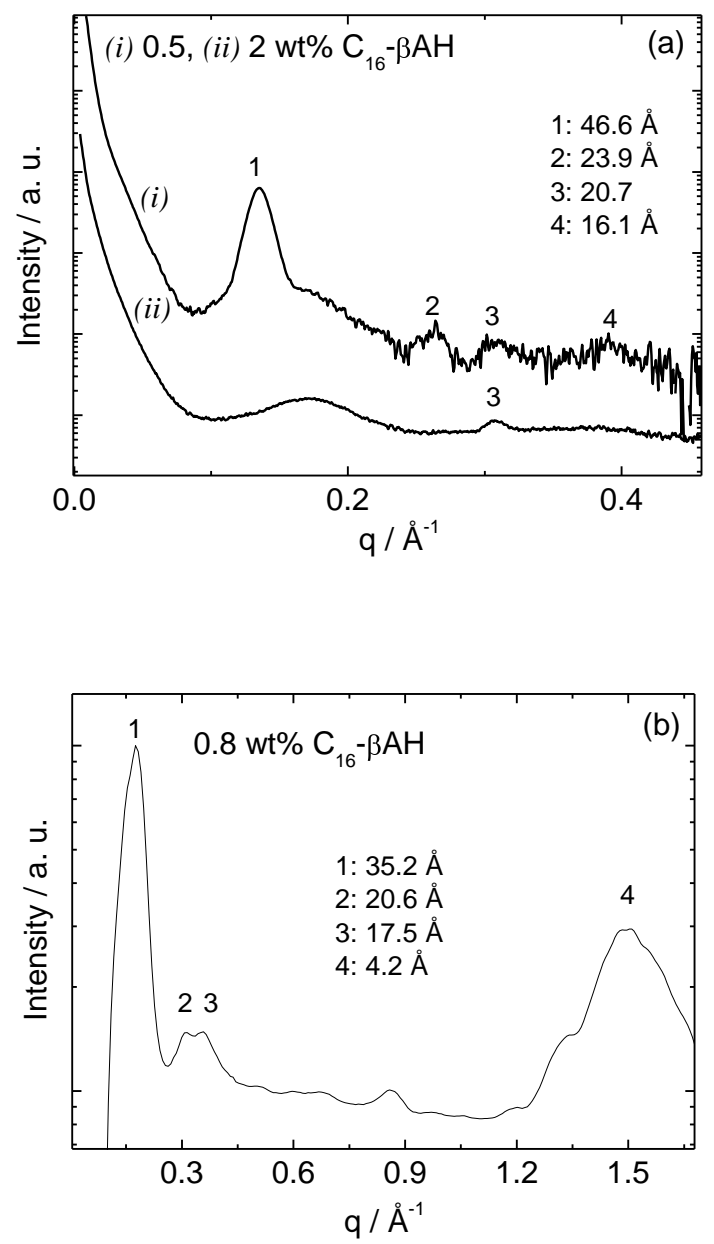

Figure 3. (a) SAXS data for 0.5 and $2 \mathrm{wt} \% \mathrm{C}_{16}-\beta A H$. Data for $0.5 \mathrm{wt} \%$ has been shifted in order to enable visualization. (b) XRD data for a stalk dried from a 0.8 wt \% $\mathrm{C}_{16}-\beta \mathrm{AH}$ solution. 


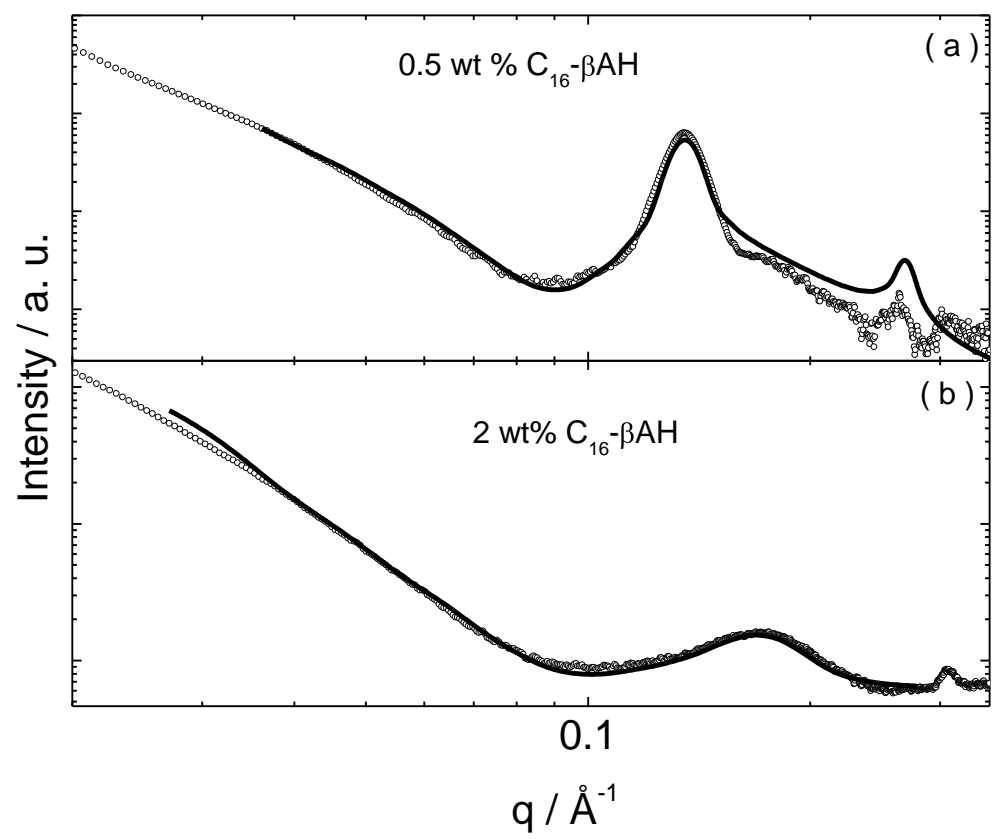

Figure 4. Fitting of the SAXS curves for (a) 0.5 and (b) 2 wt $\% C_{16}-\beta A H$ in Figure $3 a$ according to a Gaussian bilayer form factor together with a modified Caillé structure factor. 
(a)

(c)

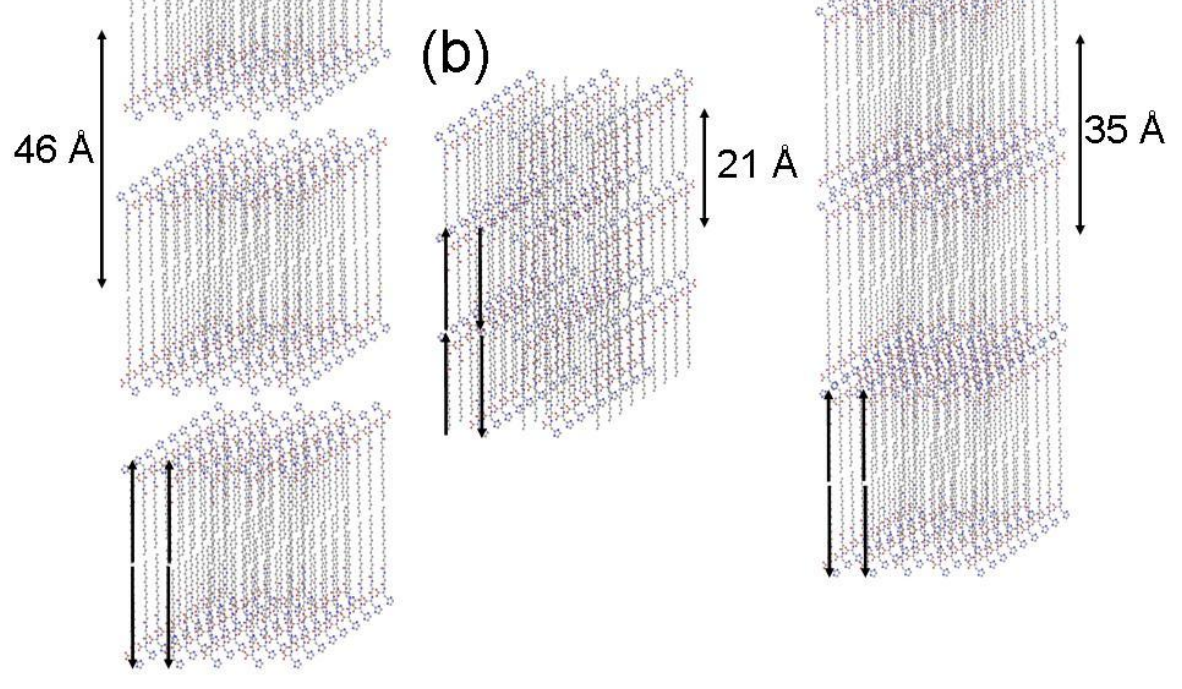

Figure 5. Model layer structures for $C_{16}-\beta A H$ in solution. 


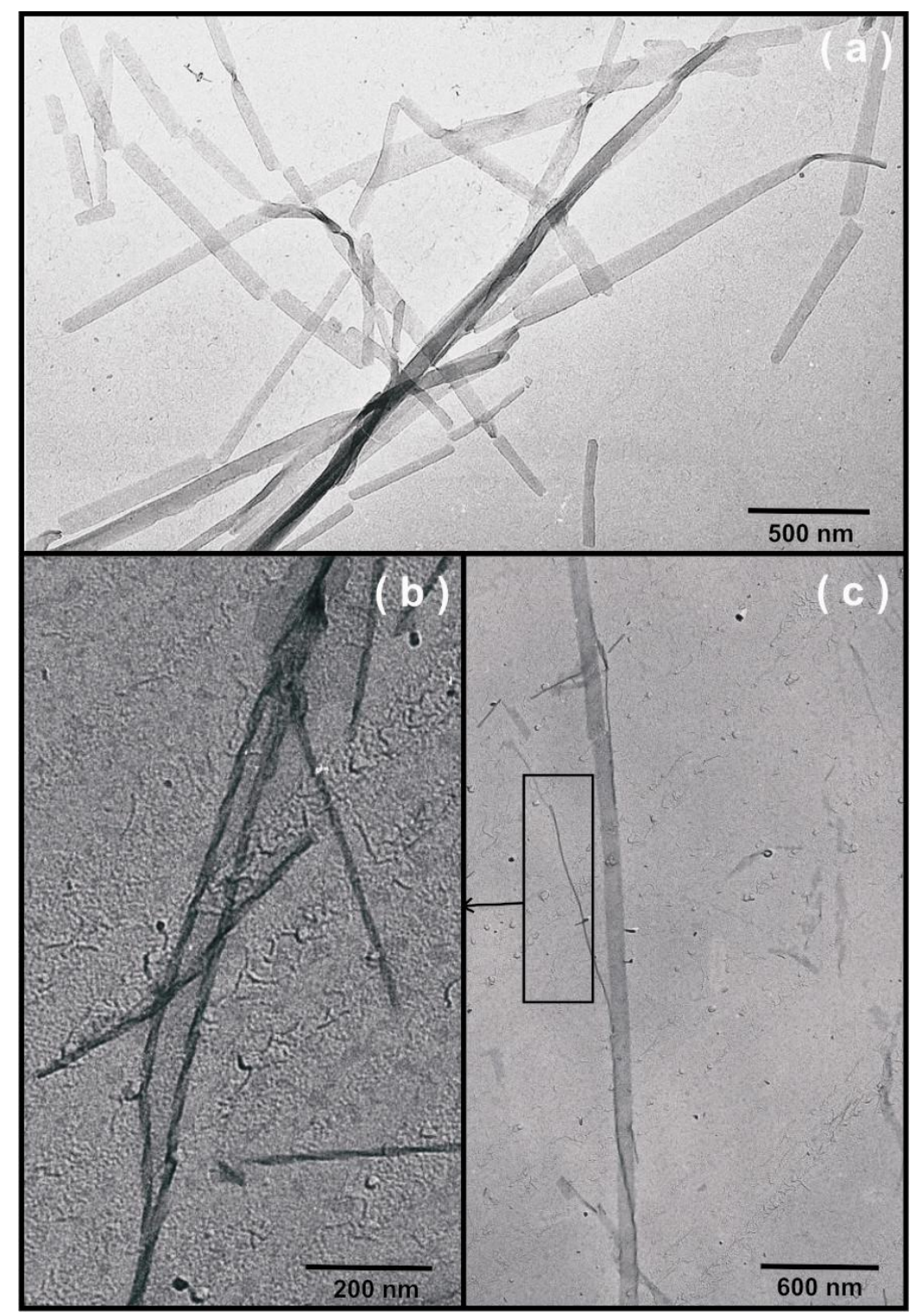

Figure 6. TEM images for (a) 0.05 and (b-c) 1 wt\% $\mathrm{C}_{16}-\beta A H$; (b) corresponds to a magnification of a twisted fibril similar to that framed in (c). 


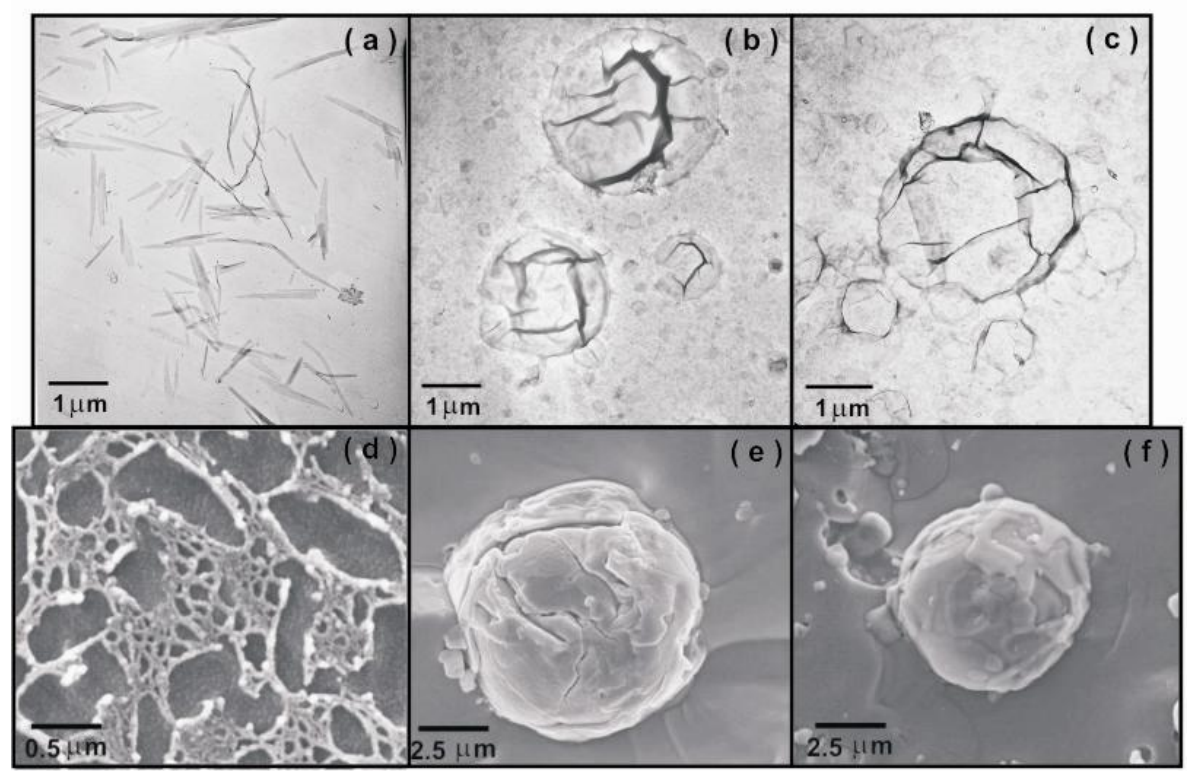

Figure 7. TEM images measured for films dried from (a) $0.03 \mathrm{wt} \% \mathrm{C}_{16}-\beta \mathrm{AH}$, (b) 1.5 $w t \%$ DPPC and (c) $1.5 \mathrm{wt} \%$ DPPC $+0.03 \mathrm{wt} \% \mathrm{C}_{16}-\beta \mathrm{AH}$. Cryo-SEM for (d) $0.03 \mathrm{wt} \%$ $\mathrm{C}_{16}-\beta A H,(e) 1.5 w t \%$ DPPC and (f) $1.5 \mathrm{wt} \% \mathrm{DPPC}+0.03 \mathrm{wt} \% \mathrm{C}_{16}-\beta A H$. 


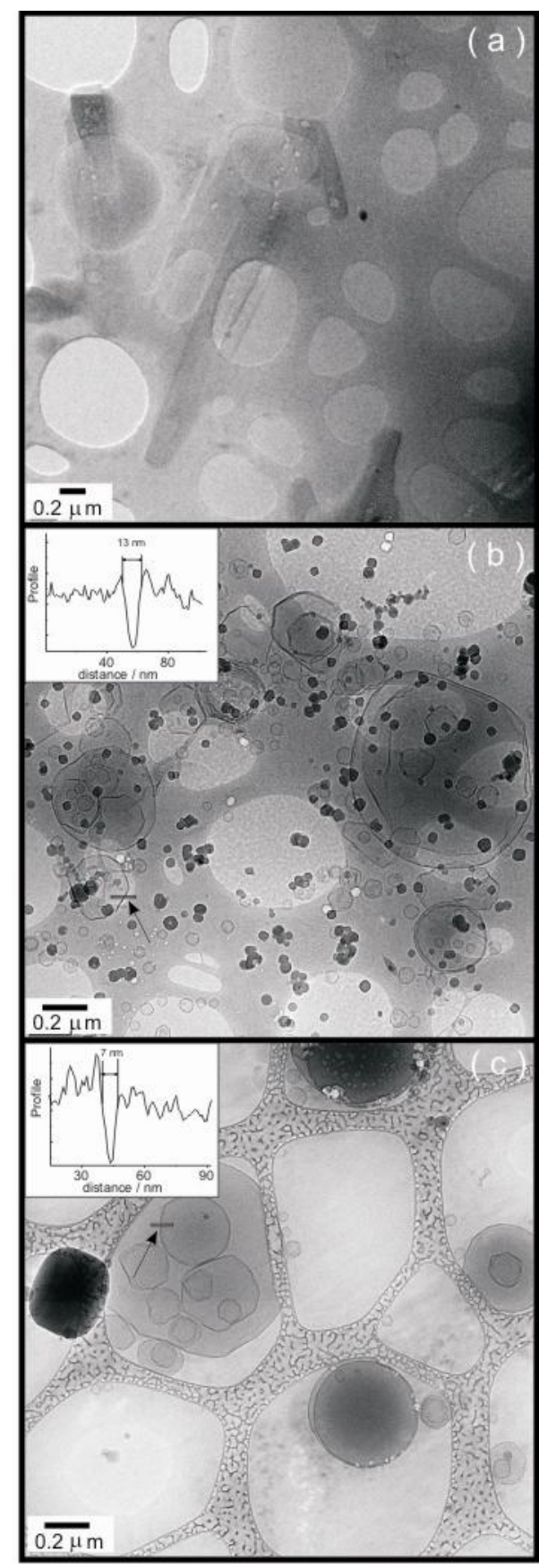

Figure 8. Cryo-TEM images for (a) $0.03 \mathrm{wt} \% \mathrm{C}_{16}-\beta \mathrm{AH}$, (b) $1.5 \mathrm{wt} \%$ DPPC and (c) $1.5 \mathrm{wt} \% \mathrm{DPPC}+0.03 \mathrm{wt} \% \mathrm{C}_{16}-\beta \mathrm{AH}$. (b) and (c) The arrows point to the region corresponding to the intensity profile. 


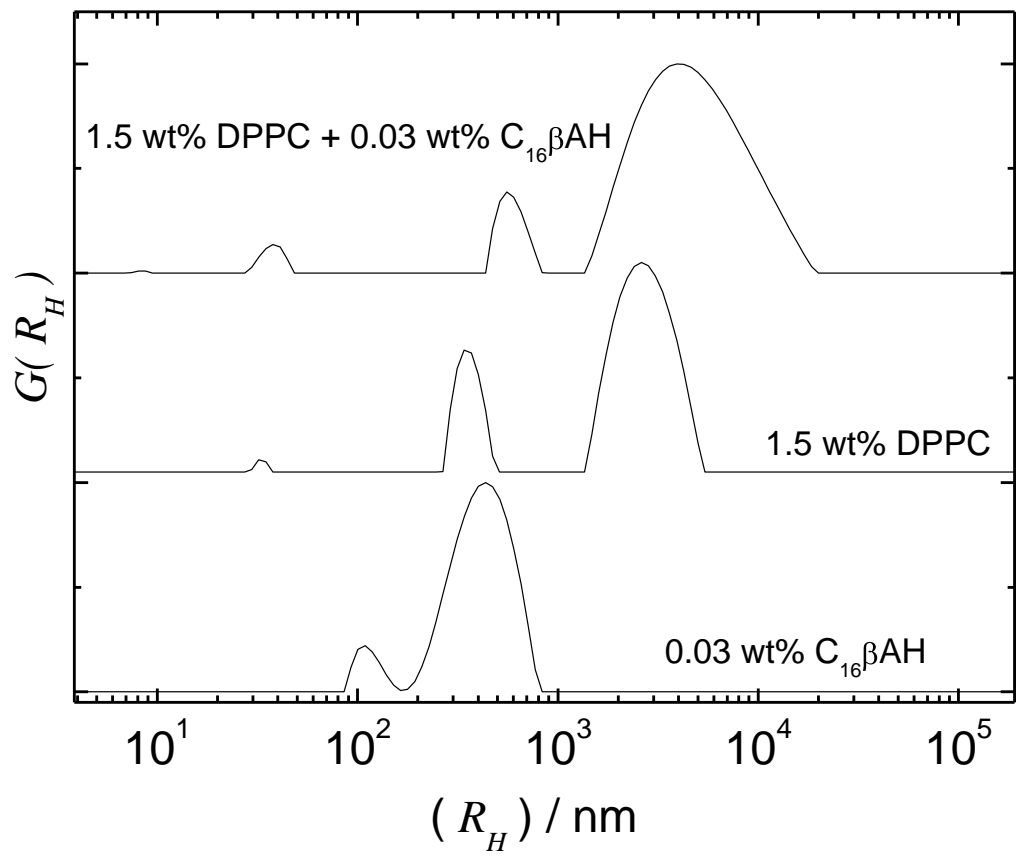

Figure 9. Distribution of hydrodynamic radii calculated for $0.03 \mathrm{wt} \% \mathrm{C}_{16}-\beta \mathrm{AH}, 1.5$ $w t \%$ DPPC and $1.5 w t \%$ DPPC $+0.03 w t \% \mathrm{C}_{16}-\beta A H$ 


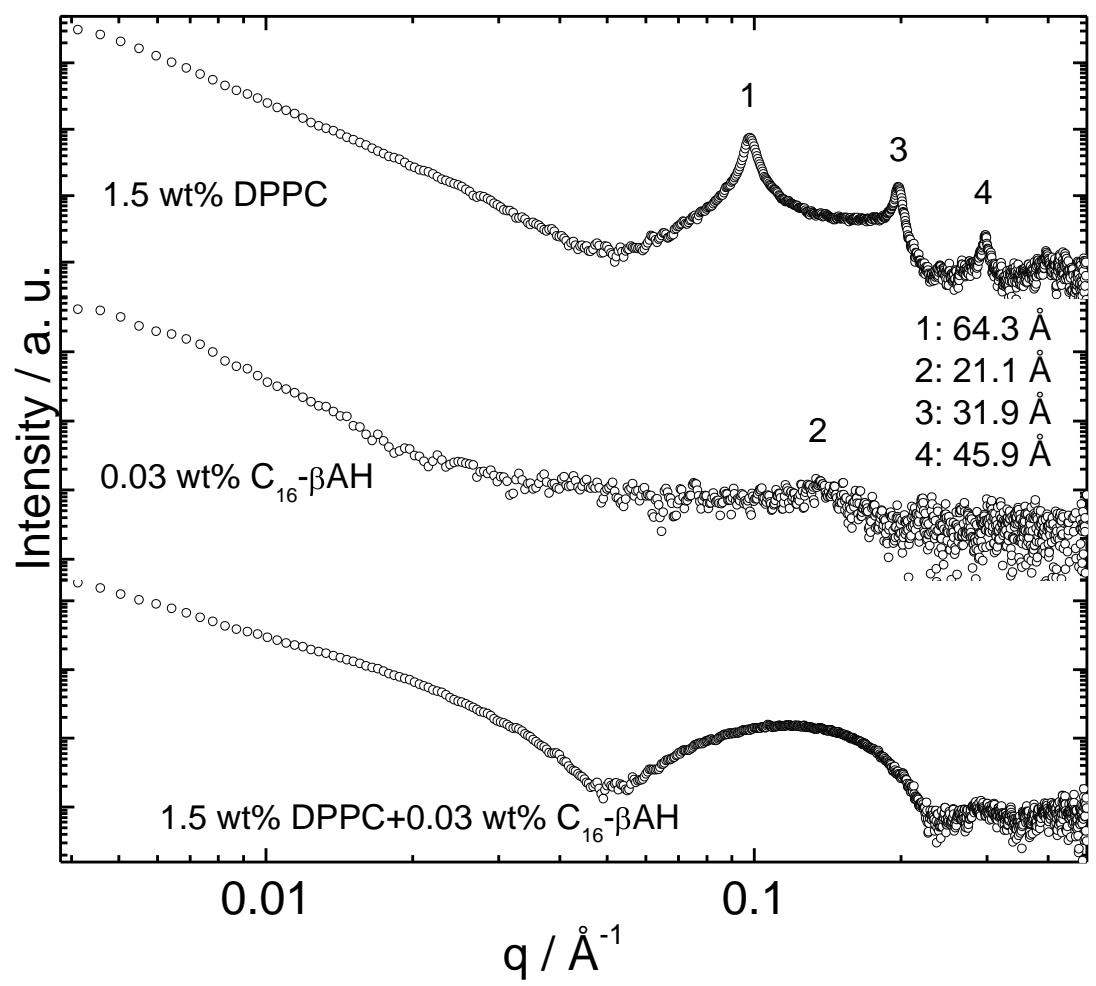

Figure 10. SAXS profiles for $0.03 \mathrm{wt} \% \mathrm{C}_{16}-\beta A H, 1.5 \mathrm{wt} \% \mathrm{DPPC}$ and $1.5 \mathrm{wt} \%$ $\mathrm{DPPC}+0.03 \mathrm{wt} \% \mathrm{C}_{16}-\beta \mathrm{AH}$. The SAXS curves have been shifted in order to enable visualization of the data. 


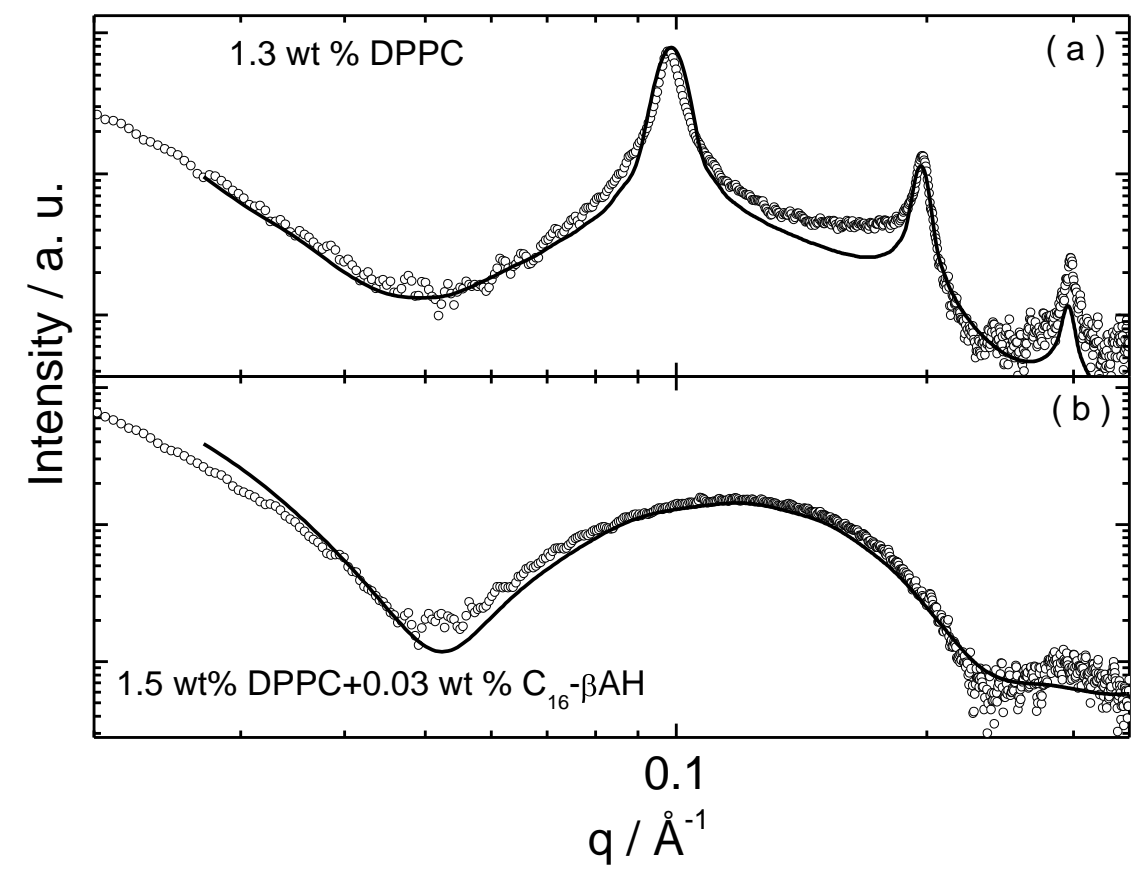

Figure 11. Fitting of the SAXS curves for (a) $1.5 \mathrm{wt} \%$ DPPC and (b) $1.5 \mathrm{wt} \%$ DPPC+ $0.03 \mathrm{wt} \% \mathrm{C}_{16}-\beta \mathrm{AH}$ in Figure 9 according to a Gaussian bilayer form factor together with a modified Caillé structure factor.

\section{References}


(1) Bonfanti, L.;Peretto, P.;De Marchis, S.;Fasolo, A. Prog. Neurobiol. 1999, 59, 333-353.

(2) Gariballa, S. E.;Sinclair, A. J. Age and Ageing 2000, 29, 207-210.

(3) Mehta, A. D.;Seidler, N. W. Journal of Enzyme Inhibition and Medicinal Chemistry 2005, 20, 199-203.

(4) Hipkiss, A. R.;Michaelis, J.;Syrris, P. FEBS Lett. 1995, 371, 81-85.

(5) Brownson, C.;Hipkiss, A. R. Free Radical Biology and Medicine 2000, 28, 1564-1570.

(6) Boldryev, A. A.;Dupin, A. M.;Bunin, A. Y.;Babizhaev, M. A.;Severin, S. E. Biochem. Int. 1987, 15, 1105-1113.

(7) McFarland, G. A.;Holliday, R. Experimental Cell Research 1994, 212, $167-$ 175.

(8) Torreggiani, A.;Fini, G.;Bottura, G. Journal of Molecular Structure 2001, 565-566, 341-346.

(9) Torregiani, A.;Bonora, S.;Fini, G. Biopolymers 2000, 57, 352-364.

(10) Lenz, G. R.;Martell, A. E. Biochemistry 1964, 3, 750-753.

(11) Lenz, G. R.;Martell, A. E. Biochemistry 1964, 3, 745-750.

(12) Hobart, L. J.;Seibel, I.;Yeargans, G. S.;Seidler, N. W. Life Sci. 2004, 75, $1379-$ 1389.

(13) Seidler, N. W.;Yeargans, G. S.;Morgan, T. G. Arch. Biochem. Biophys. 2004, 427, 110-115.

(14) Attanasio, F.;Cataldo, S.;Fisichella, S.;Nicoletti, S.;Nicoletti, V. G.;Pignataro, B.;Savarino, A.;Rizzarelli, E. Biochemistry 2009, 48, 6522-6531.

(15) Castelletto, V.;Cheng, C.;Greenland, B. W.;Hamley, I. W.;Harris, P. J. F. Langmuir 2011, 27, 2980-2988

(16) Hamley, I. W. Soft Matter 2011, 7, 9533-9534

(17) Matson, J. B.;Zha, R. H.;Stupp, S. I. Current Opinion in Solid State \& Materials Science 2011, 15, 225-235

(18) Silva, G. A.;Czeisler, C.;Niece, K. L.;Beniash, E.;Harrington, D. A.;Kessler, J. A.;Stupp, S. I. Science 2004, 303, 1352-1355.

(19) Tysseling-Mattiace, V.;Sahni, V.;Niece, K.;Birch, D.;Czeisler, C.;Fehlings, M.;Stupp, S.;Kessler, J. J. Neurosci. 2008, 28, 3814-3823.

(20) Shah, R.;Shah, N.;Lim, M.;Hsieh, C.;Nuber, G.;Stupp, S. PNAS 2010, 107, 3293-3298

(21) Bond, C.;Angeloni, N.;Harrington, D.;Stupp, S.;McKenna, K.;Podlasek, C. Journal of Sexual Medicine 2011, 8, 78-89.

(22) Lintner, K.;Peschard, O. International Journal of Cosmetic Science 2000, 22, 207-218

(23) Szoka, F.;Papahadjopoulos , D. PNAS 1978, 75, 4194-4198.

(24) David, G.;Perez, J. J. Appl. Cryst. 2009, 42, 892-900.

(25) Pabst, G.;Rappolt, M.;Amenitsch, H.;Laggner, P. Physical Review E 2000, 62, 4000-4008.

(26) Zhang, R.;Suter, R. M.;Nagle, J. F. Phys. Rev. E 1994, 50, 5047-5060.

(27) Caillé, M. A. C. R. Acad. Sci. Paris 1972, 274, 891-893.

(28) Zhang, R.;Suter, R. M.;Nagle, J. F. Phys. Rev. E 1964, 50, 5047-5060.

(29) Berne, B. J.;Pecora, R. (1976) Dynamic Light Scattering, Wiley-Interscience, New York.

(30) Provencher, S. W. Makromoleculaire Chemie 1979, 180, 201.

(31) www.molinspiration.com. (2010). 
(32) Johnsson, M.;Hansson, P.;Edwards, K. J. Phys. Chem. B 2001, 105, 84208430 .

(33) Wilhelm, M.;Zhao, C.-L.;Wang, Y.;Xu, R.;Winnik, M. A.;Mura, J.-L.;Riess, G.;Croucher, M. D. Macromolecules 1991, 24, 1033-1040.

(34) Astafieva, I.;Zhong, X. F.;Eisenberg, A. Macromolecules 1993, 26, 73397352.

(35) Astafieva, I.;Khogaz, K.;Eisenberg, A. Macromolecules 1995, 28, 7127-7134.

(36) Johnsson, M.;Silvander, M.;Karlsson, G.;Edwards, K. Langmuir 1999, 15, 6314-6325.

(37) (Innovagen's Peptide Property Calculator) Copyright (C) 2012 Innovagen AB.

(38) Yang, Z.;Xu, B. Chemical Communications 2004, 2424-2425

(39) Yang, Z.;Gu, H.;Fu, D.;Gao, P.;Lam, J. K. W.;Xu, B. Adv. Mat. 2004, 16, 1440.

(40) Cheng, G.;Castelletto, V.;Jones, R.;Connon, C. J.;Hamley, I. W. Soft Matter 2010, in press.

(41) Bellamy, L. J. (1975) The Infra-Red Spectra of Complex Molecules, London.

(42) Zhang, Y. P.;Lewis, R.;Hodges, R. S.;McElhaney, R. N. Biochemistry 1992, 31, 11572-11578.

(43) Reis, O.;Winter, R.;Zerda, T. W. Biochimica et Biophysica Acta Biomembranes 1996, 1279, 5-16.

(44) Moore, D. J.;Rerek, M. E.;Mendelsohn, R. J. Phys. Chem. B 1997, 101, 89338940.

(45) Hamley , I. W. Angewandte Chemie, International Edition in English 2007, 46, 8128-8147.

(46) Safinya, C. R.;Sirota, E. B.;Bruinsma, R. F.;Jeppesen, C.;Plano, R. J.;Wenzel, L. J. Science 1993, 261, 588-591.

(47) Kohlbrecher, J.;Bressler, I. (2011) Software package SASfit for fitting smallangle scattering curves.

(48) Castelletto, V.;Hamley, I. W.;Adamcik, J.;Mezzenga, R.;Gummel, J. Soft Matter 2012, 8, 217-226.

(49) Khosravi-Darani, K.;Pardakhty, A.;Honarpisheh, H.;Rao, V. S. N. M.;Mozafari, M. R. Micron 2007, 38, 804-818.

(50) Kim, S. H.;Haimovich-Caspi, L.;Omer, L.;Talmon, Y.;Franses, E. I. Journal of Colloid and Interface Science 2007, 311, 217-227.

(51) Nagle, J. F.;Tristram-Nagle, S. Biochimica et Biophysica Acta 2000, 1469 , 159-195.

(52) Sun, W.-J.;Tristam-Nagle, S.;Suter, R. M.;Nagle, J. F. Biophysical Journal 1996, 71, 885-891.

(53) McManus, J. J.;Radler, J. O.;Dawson, K. A. Langmuir 2003, 19, 9630-9637.

(54) Madden, T. D.;Tilcock, C. P. S.;Wong, K.;Cullist, P. R. Biochemistry 1988, 27, 8724-8730.

(55) Haris, P.;Chapman, D. Biopolymers 1995, 37, 251-263.

(56) Stuart, B. (1997) Biological Applications of Infrared Spectroscopy, Wiley, Chichester.

(57) Rosler, A.;Klok, H.-A.;Hamley , I. W.;Castelletto, V.;Mykhaylyk, O. O. Biomacromolecules 2003, 4, 859-863.

(58) Miyazawa, T.;Blout, E. R. Journal of the American Chemical Society 1961, 83, 712-719.

(59) Gaussier, H.;Morency, H.;Lavoie, M. C.;Subirade, M. Appl. Environ. Microbiol. 2002, 68, 4803-4808. 
(60) Pelton, J. T.;McLean, L. R. Anal. Biochem. 2000, 277, 167-176.

(61) Lukton, A.;Sisti, A. The Journal of Organic Chemistry 1961, 26, 617-619.

(62) Baran, E. J.;Parajon-Costa, B. S.;Rojo, T.;Saez-Puche, R.;Fernandez,

F.;Totaro, R. M.;Apella, M. C.;Etcheverry, S. B.;Torre, M. H. Journal of Inorganic Biochemistry 1995, 58, 279-289. 


\section{Table of Contents Figure}

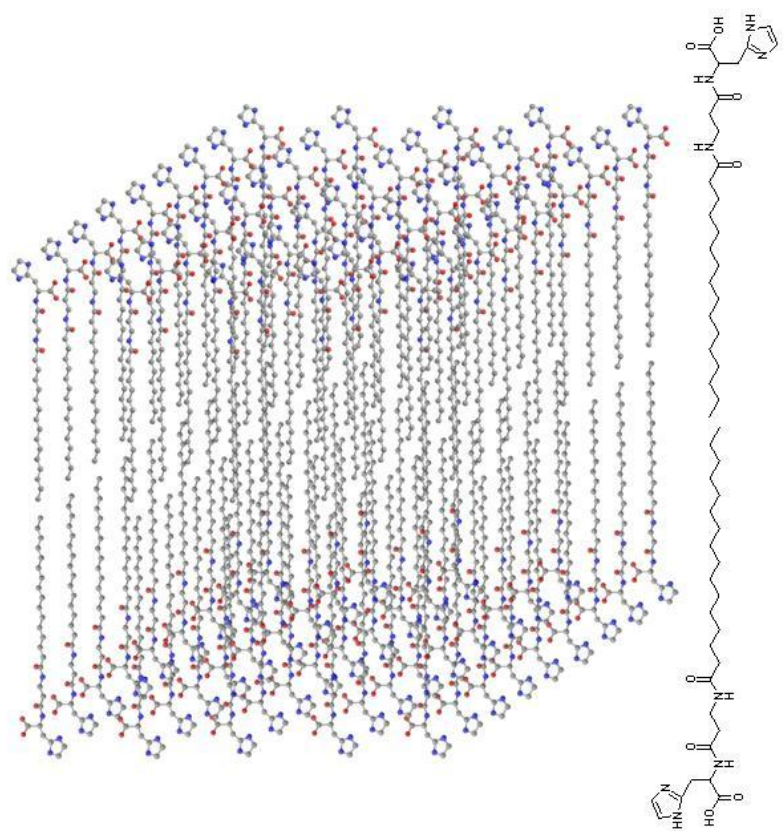

